\title{
Administrator and Faculty Perceptions of Incivility and Conflict in the Workplace: A Higher Education Study
}

Stacey McLeran Kendig

West Virginia University

Follow this and additional works at: https://researchrepository.wvu.edu/etd

\section{Recommended Citation}

Kendig, Stacey McLeran, "Administrator and Faculty Perceptions of Incivility and Conflict in the Workplace: A Higher Education Study" (2013). Graduate Theses, Dissertations, and Problem Reports. 3630.

https://researchrepository.wvu.edu/etd/3630

This Dissertation is protected by copyright and/or related rights. It has been brought to you by the The Research Repository @ WVU with permission from the rights-holder(s). You are free to use this Dissertation in any way that is permitted by the copyright and related rights legislation that applies to your use. For other uses you must obtain permission from the rights-holder(s) directly, unless additional rights are indicated by a Creative Commons license in the record and/ or on the work itself. This Dissertation has been accepted for inclusion in WVU Graduate Theses, Dissertations, and Problem Reports collection by an authorized administrator of The Research Repository @ WVU.

For more information, please contact researchrepository@mail.wvu.edu. 
Administrator and Faculty Perceptions of Incivility and Conflict in the Workplace:

A Higher Education Study

\title{
Stacey McLeran Kendig
}

A dissertation submitted to the College of Education and Human Services at West Virginia University in partial fulfillment of the requirement for the degree of

Doctor of Education

in

Educational Leadership Studies in Higher Education

\author{
Paul Chapman, Ph.D., Chair \\ Neal Shambaugh, Ph.D. \\ Richard Walls, Ph.D. \\ Jerry Jones, Ph.D. \\ Kim Yousey, Ph.D. \\ Dawne Raines Burke, Ph.D.
}

Department of Curriculum \& Instruction/Literacy Studies

Morgantown, WV

2013

Keywords: Incivility; conflict; administrators; faculty; higher education 


\section{ABSTRACT \\ Administrator and Faculty Perceptions of Incivility in the Workplace: \\ A Higher Education Study}

Stacey M. Kendig

Uncivil workplace behavior in the higher education environment is counterproductive for achieving institutional goals. Prevailing uncivil behaviors frequently result in unresolved conflict, a focus of various researchers since the mid 1970's (Andersson \& Pearson, 1999; Martin \& Hine, 2005; Pierre \& Peppers, 1976; Pietersen, 2005; and Twale \& DeLuca, 2008). This study was designed to examine administrator and faculty members' perceptions of uncivil workplace behaviors and organizational culture. The study further examined the relationship between incivility and organizational culture. The Uncivil Workplace Behavior Questionnaire (Martin \& Hine, 2005) and the K \& C Organizational Culture Instrument (Kendig \& Chapman, 2012) were combined and distributed to a small sample of administrators and faculty members in higher education. The respondents included 34 administrators and 151 faculty members from three similar Public 4-Year Institutions of Higher Education (Carnegie Classification, 2010). Results indicate that perceptions of incivility and organizational culture between administrators and faculty members are not different. This study can serve as a contribution to the professional development efforts of administrators and faculty members in higher education. 


\section{Dedication and Acknowledgements}

I dedicate this dissertation to my husband and my entire family. The support and encouragement I received from the beginning of my endeavor has been overwhelming. Thank you everyone and I love you all.

I want to acknowledge and thank Dr. Paul Chapman for agreeing to serve as my committee chair and work with me diligently to complete my degree. Thank you for all of your encouragement and words of wisdom. Your time and constant efforts in working with me are greatly appreciated.

Thank you to Dr. Richard Walls for your time and energy working with me on my methods and analysis. Your words of wisdom and encouragement as I moved forward to the completion of my dissertation are greatly appreciated.

I also acknowledge and thank the other members of my committee:

Dr. Neal Shambaugh, Dr. Kim Yousey, Dr. Dawne Raines Burke, and Dr. Jerry Jones for agreeing to serve on my committee and for their patience and encouragement while working with me. Your input and words of encouragement during this process were greatly appreciated.

I am very grateful to colleague Dr. Andro Barnett for continuing to encourage me to pursue this degree. I could not have done it without his continued support, help, and dedication to my success. I also want to acknowledge and thank several other colleagues from the Shepherd University community: Dr. Dorothy Hively, Dr. Neil Brasher, Dr. Sally Brasher, Dr. J. Michael Jacobs, Dr. Anna DeVito, Dr. Rick Gibson, Mr. Ed Finchem, Mr. Chip Ransom, Miss Leslie Lopez, Coach Melanie Ford, Dr. Charlotte Anderson, Dr. Laura Clayton, Dr. Becky Mercado, Mrs. Barbara Kemerer, Dr. Robert Warburton, Mr. Keith Worrell, Dr. Jared Androzzi, Dr. Rosie 
Barretta, Dr. Rhonda Hovatter, Dr. Greg Place, and all of my colleagues in the Department of Health, Physical Education, Recreation and Sport.

Finally, I want to thank and acknowledge so many of my personal friends and colleagues who have been my cheerleaders, supporters, and encouragers of my success. Thank you to all of you who have been a part of this tremendous effort. 


\section{Contents}

Dedication and Acknowledgements................................... iii

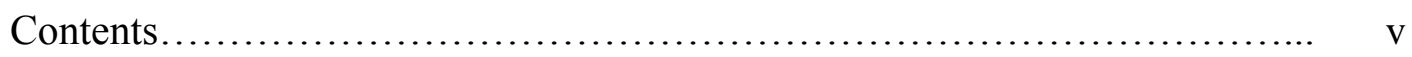

List of Tables and Figures $\ldots \ldots \ldots \ldots \ldots \ldots \ldots \ldots \ldots \ldots \ldots \ldots \ldots \ldots \ldots \ldots \ldots \ldots \ldots \ldots \ldots$, vii

Background of the Study .......................................... 1

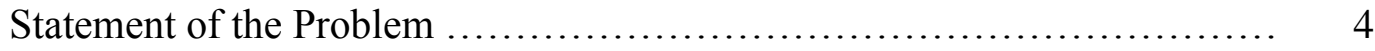

Purpose of the Study ............................................. 5

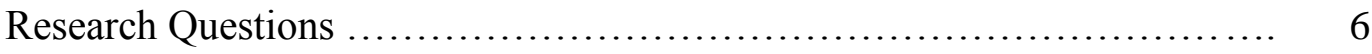

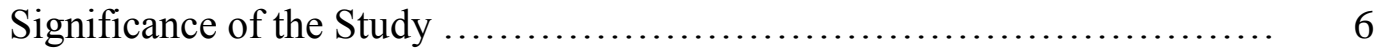

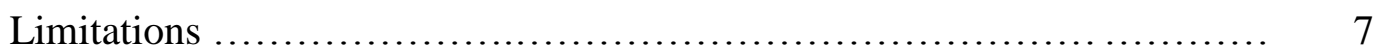

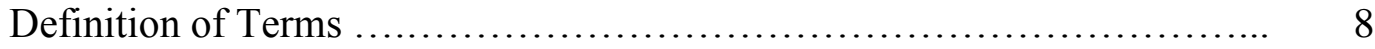

Review of the Literature............................................... 11

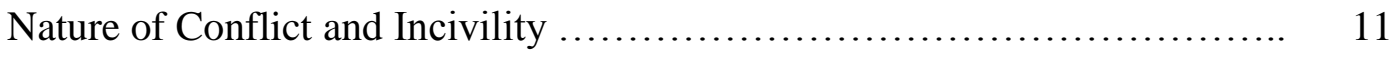

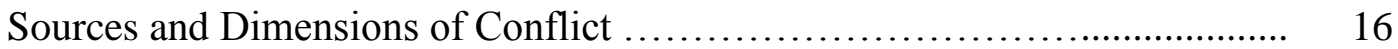

Causes of Conflict ............................................ 24

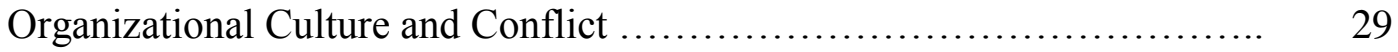

Summary of the Literature Review ................................ 34

Research Method ................................................. 36

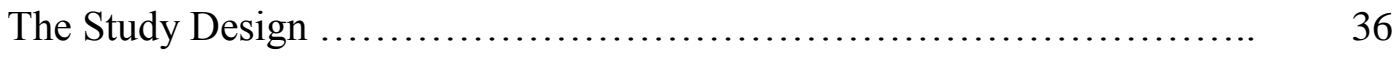

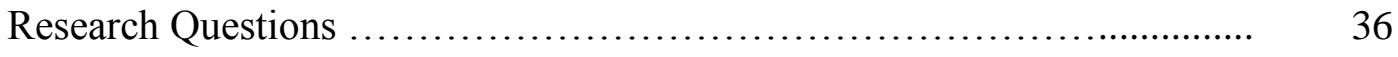

Participants of the Study ....................................... 37

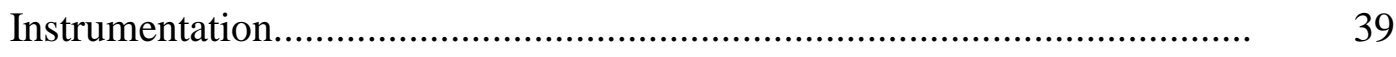

Data Collection................................................................................... 41 


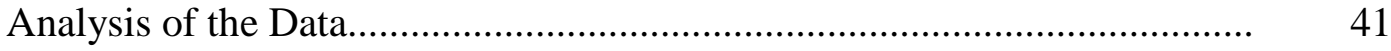

Summary of the Methodology ....................................... 43

Results and Data Analysis........................................ 44

Survey Responses and Demographic Information.................... 45

Statistical Analysis of the Data................................... 46

Types of Analysis............................................ 52

Major Findings.............................................. 53

Summary of the Data Analysis................................... 67

Summary and Discussion......................................... $\quad 69$

Summary of the Study.......................................... 69

Discussion of the Findings....................................... $\quad 70$

Conclusions.................................................. 80

Recommendations for Practice.................................. 83

Recommendations for Future Research.............................. 84

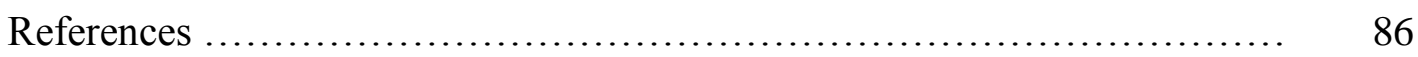

Appendix A: Uncivil Workplace Behavior Questionnaire................. 91

Appendix B: K \& C Organizational Culture Instrument.................. 92

Appendix C: Permission to use UWBQ ................................ 93

Appendix D: Administrator Cover Letter................................ 94

Appendix E: Administrator Reminder Letter.......................... 95

Appendix F: Faculty Member Letter.................................. 96

Appendix G: Faculty Member Reminder Letter........................ 97 


\section{List of Tables and Figures}

\begin{tabular}{|c|c|c|}
\hline Table & & Page \\
\hline 1 & Framework of Organizational Culture... & 33 \\
\hline 2 & 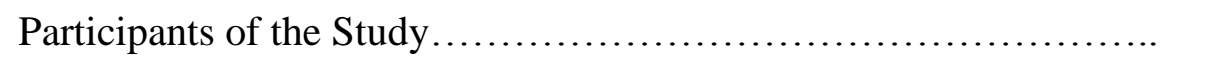 & 39 \\
\hline 3 & Professional Status of Respondents............................. & 45 \\
\hline 4 & UWBQ Factors and Score Range................................... & 46 \\
\hline 5 & UWBQ Factor Items..... & 48 \\
\hline 6 & K \& C-OCI Factors and Score Range..... & 49 \\
\hline 7 & $\mathrm{~K} \& \mathrm{C}-\mathrm{OCI}$ Factor Items..... & 50 \\
\hline 8 & UWBQ and $\mathrm{K} \& \mathrm{C}-\mathrm{OCI}$ Equality of Variance Test................... & 51 \\
\hline 9 & Hostility Mean Scores of Faculty \& Administrators.................. & 54 \\
\hline 10 & Hostility $t$-test for Equality of Means........... & 54 \\
\hline 11 & Privacy Invasion Mean Scores of Faculty \& Administrators........... & 55 \\
\hline 12 & Privacy Invasion $t$-test for Equality of Means...................... & 55 \\
\hline 13 & Exclusionary Behavior Mean Scores of Faculty \& Administrators...... & 56 \\
\hline 14 & Exclusionary Behavior $t$-test for Equality of Means.................. & 56 \\
\hline 15 & Gossiping Mean Scores of Faculty \& Administrators................. & 57 \\
\hline 16 & Gossiping $t$-test for Equality of Means... & 57 \\
\hline 17 & Composite Mean Scores for UWBQ. & 58 \\
\hline 18 & Composite $t$-test for Equality of Means.... & 58 \\
\hline \multirow[t]{2}{*}{19} & Organizational History and Environment Mean Scores of Faculty and & \\
\hline & 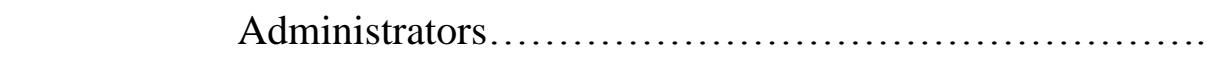 & 59 \\
\hline 20 & Organizational History and Environment $t$-test for Equality of Means... & .59 \\
\hline
\end{tabular}


Administrator and Faculty Perceptions of Incivility and Conflict in the Workplace:

\section{A Higher Education Study \\ Background of the Study}

Incivility in the higher education academic environment is counterproductive for achieving the institutional goals. Prevailing uncivil behaviors frequently result in unresolved conflict, a focus of various researchers since the mid 1970's (Andersson \& Pearson, 1999; Martin \& Hine, 2005; Pierre \& Peppers; 1976; Pietersen, 2005; Twale \& Deluca, 2008).

Consequently, this study explores the sources, dimensions, and causes of uncivil behaviors as they relate to conflict within institutions of higher education. Moreover, the study explores administrator and faculty perceptions with regard to institutional culture and their corresponding relationship to incivility. Uncivil behaviors within small and large groups of individuals can be perceived as unproductive in trying to meet organizational goals and objectives. Prolonged and repeated participation in uncivil acts by administrators and faculty in higher education organizations creates not only a culture of conflict but also institutional dysfunction. These uncivil acts share certain sets of behavioral commonalities which overlap and often create certain patterns of behavior that have clear hostile intent that may occur over a period of time (Penney \& Spector, 2005).

Due to the cultural diversity associated with institutional development, as it pertains to administrators and faculty within institutions of higher education, it is important to investigate how institutional culture can create higher levels of conflict in achieving personal satisfaction or organizational agendas. It is the leaders' responsibility to establish and nurture a culture of trust and stability. Leaders who understand the dynamics of uncivil behaviors within their institutional culture need to have skills and knowledge that allow them to counter the 
dysfunctional culture. Higher education leaders must rightly recognize and define the problem of uncivil behaviors that result in conflict. Kefela (2010) contends that utilizing skills such as conflict management styles, mentally representing the problem, formulating strategies to solve the problem, and monitoring and evaluating the solution to the problem, is productive in reaching organizational goals and objectives. These types of skills set institutional leaders on a path toward building a culture of civility embedded in the values and beliefs of the members of the institution.

According to Pierre and Peppers (1976), conflict occurs between individual humans or small and large groups of humans. Hence, they believe that if differences exist among individuals and may not be handled adequately, then it is highly likely that the individuals or groups involved are not able to come together in understanding and cooperating with one another.

Kefela (2010) contends that the organization's culture, in fact, has an impact on the development and implementation of its strategy and achieving the institution's goals and objectives. When institutions and organizations are intentionally cultivated, the organization's ability to execute strategies improves dramatically.

One early organizational culture predecessor, Edgar Schein conducted many studies, which opened up the contextual background for the study of organizational behavior. Schein investigations assert that an organization's culture develops to help it cope with its environment (Schein, 2010). Schein contends that many of the problems organizational leaders are confronted with are the result of their inability to evaluate the organization's culture. When leaders attempt to implement a strategic plan or a new vision; they often fail because their strategies are not consistent with the organization's existing culture. One example of this would 
be if a new provost were to step into an institution of higher education prepared to shake things up by implementing major and abrupt changes, that person often experiences first hand the resistance to change and hence fail after several repeated, succeeding attempts to institute change within the organizational context (Schein, 2010). In continuing research conducted by Schein, he supports that organizational culture is a complex context and is difficult to understand particularly from within the organization's culture-specific demands. However, to gain a better understanding of the term, Schein divides organizational culture into three levels: (a) behavior and artifacts, (b) espoused values, mission, and (c) assumptions and beliefs. If organizational leaders have a true understanding of the institution's culture based on these characteristics, they are increasingly informed and perhaps better aligned to implement successful conflict resolution within the context of the existing organizational culture.

One of the primary responsibilities of leaders in higher education is to maintain organizational culture and characteristics that encourage and reward collaborative efforts among administrators and faculty (Kefela, 2010). Nord (1972) during his research on culture, referred to culture as the grand total of the objects, ideas, knowledge, ways of doing things, habits, values, and attitudes that every generation passes onto the next. Hence, leadership is a critical component in maintaining the institution's mission, vision, core values, setting an example for others by demonstrating cultural elements: beliefs, values, actions, and measures that guide the culture's behavior. Leadership is defined as the process by which a person has influence on others to accomplish institutional goals and objectives while simultaneously directing the organization in a unified, cohesive, and coherent way (Kefela, 2010). This process is to be carried out by applying attributes such as values, beliefs, ethics, and character; therefore leaders 
will be better informed and have a clearer understanding of how to counter the culture of workplace incivility while providing guidance to conflict resolution (Kefela, 2010).

Davidson and Wood (2004) suggested that in many situations involving conflict, there are underlying issues that may not be clearly recognized or articulated by the parties involved. Therefore, solutions may only be found by going beyond initial bargaining positions of the parties involved. Whereas efforts to further explore and determine needs and concerns of the involved individuals, can function to generate more creative alternatives in the enduring effort to promote more normative behaviors for more cooperative ends.

Deutsch, Coleman and Marcus (2006), conducting studies in conflict resolution, assert that if participants were trained to convert norms of cooperative behavior, even during the onset of conflict, it would affect skill development that facilitates effective cooperation. Some of the skills might include but are not limited to: (a) placing disagreements in perspective; (b) address concrete issues; (c) not make personal attacks and try to understand others' views and perspectives, and (d) build upon the ideas of the others while emphasizing positive possibilities of conflict resolution.

\section{Statement of the Problem}

With workplace incivility increasing (Pearson \& Porath, 2005), the effects of uncivil behaviors in organizations and institutions of higher education can have severe consequences. In a study conducted by Ferriss (2002), there are several factors involved in the acts of incivility which are: self-control, self-restraint, self-discipline, and the degree to which individuals involved in such incidents demonstrate restraining capacities, which, in most cases, advances with age and maturation. Incivility gives rise to conflict, and conflicts demand responses from leaders eliminating negative effects. In an effort to investigate issues of conflict and workplace 
incivility, it was relevant to examine sources, dimensions, and causes of uncivil behavior then draw conclusions regarding differentials for how it is administrators and faculty perceive conflict, which is often enhanced through organizational tendencies when humans are promoted into positions of power (Barlett, Barlett, \& Reio, 2008).

The problem is that although this phenomenon of incivility has been studied, it is not well understood in terms of the how leaders and faculty members in higher education perceive uncivil behavior and organizational culture.

\section{Purpose of the Study}

The purpose of this study was to contribute to existing literature regarding incivility in higher education. Furthermore, the study's purpose was to examine the (a) sources, (b) dimensions, and (c) causes of uncivil behavior in order to determine if there were differences between administrators and faculty members' perceptions of incivility/conflict in institutions of higher education. The study also provided an increased depth of knowledge directly based upon the uncivil behavior phenomenon previously studied. Surveys were implemented to measure incivility perceptions against the larger, guiding framework of institutional culture in three public higher education institutions. Included in the study were representatives from within the full range of the institution's systematic, operating architecture of administrators, deans, department chairs, and full-time instructional faculty -tenured and non-tenured alike. The study specifically included higher education employees in order to ascertain perceptual variances between executive administrative officers and instructional, classroom faculty. The study further investigated perceptual variances in the definitive context of organizational culture and conflict. 


\section{Research Questions}

The following research questions (RQ) were developed to frame the study. The study then examined: (a) perceptions of incivility between administrative officers and faculty members, (b) perceptions of institutional culture between administrative officers and faculty members, and (c) perceived relationships between incivility and culture.

RQ 1: Do administrators and faculty members perceive incivility/conflict differently?

RQ 2: Do administrators and faculty members perceive organizational culture differently?

RQ3: Are there relationships between the institution's perceived culture and incivility/conflict?

\section{Significance of the Study}

With the increasing interest in workplace incivility, causes of uncivil behaviors in the workplace, and the negative impacts on organizations and institutions of higher education (Fox \& Stallworth, 2003; Pearson \& Porath, 2005) further research was needed. The significance of advancing the body of research on this topic was specifically supported by Cortina, Magley, Williams, and Langout (2001) who indicated that incivility in the workplace merits extensive research and organizational attention because of its harmful effects on organizations and individuals alike.

The study's aim was to promote increased understanding of the perceptions of uncivil behavior and conflict between administrators and faculty members in the context of a higher education culture. The study was also significant as it was aimed at contributing to the existing research body with regard to: (a) sources, (b) dimensions, and (c) causes of conflict leading to choices of incivility. Results and findings were examined to identify differences between 
administrator and faculty member perceptions of incivility and conflict in the contexts of higher education environments. Further, the study was significant as it was also aimed at examining the correlation between organizational culture and incivility.

Conflict is inevitable in any organized environment and therefore within institutions of higher education. Conflict occurs among human individuals in any context where the system of human dynamics generates within either larger or smaller groups. The study was significant as it specifically examined perceptions of uncivil behaviors between administrators and faculty members as well as perceptions of institutional culture and its relationships to incivility.

Organizational culture is a critical component within institutions of higher education, and thus can have a substantially increased impact on the organization's ability to develop and execute strategies in an effort to achieve organizational goals and objectives (Kefela, 2010). Therefore, this study was also significant as it examined relationships between administrative executives and instructional faculty since the quantitative hypothesis would suggest differing perceptions of uncivil workplace behavior and the correlation to institutional culture.

\section{Limitations}

The following limitations were recognized in this study:

1. The first limitation in the study is that the research only included the administrators and faculty of three four-year public institutions.

2. The second limitation in the research pertains to the bias that administrators and faculty members may have regarding their own perceptions of incivility.

3. The $\mathrm{K} \& \mathrm{C}$ Organizational Culture Instrument was created specifically for use in this study and has not been previously used. Therefore, there was no measure of reliability or validity. This instrument was not pilot tested. 
4. A final limitation of the study was the timing of dissemination of the instrument which occurred during the summer months, when many faculty and administrators are not on campus.

\section{Definition of Terms}

The following terms were used throughout the research process and referenced throughout the completion of the study. It is important for the reader to have a firm understanding of the terms and how they are connected to the study.

1. Artifacts: a visible level in organizational culture and focuses on outward manifestations of culture: prerequisites provided to executives, dress codes, level of technology utilized (and where it is utilized), and the physical layout of work spaces (Schein, 2010).

2. Assumptions: grow out of values until they become taken for granted and drop out of awareness (Schein, 2010).

3. Behaviors: can tell what a group is doing, but not why and is the most visible in organizational culture (Schein, 2010).

4. Conflict: "an interactive process manifested in incompatibility, disagreement, or dissonance within or between social entities (i.e., individual, group, organization, etc.)" (Rahim, 2011).

5. Conflict Management: "the consideration of not only the required guidance and control to keep conflict at an acceptable — yet not too high — level but also the activity to encourage proper conflict when the level is too low" (Pierre \& Peppers, 1976).

6. Culture: "a pattern of shared basic assumptions learned by a group as it solved its problems of external adaptation and internal integrations, which has worked well 
enough to be considered valid and, therefore, to be taught to new members as the correct way to perceive, think, and feel in relation to those problems" (Schein, 2010).

7. CWB (Counterproductive Workplace Behavior): refers to behavior by employees that harms an organization or its members (Spector \& Fox, 2002).

8. Fallibility: "the sources of disagreement between reasonable people are manifold. Reasonable people understand that their own judgment as well as the judgment of others may be fallible" (Deutsch, Coleman, \& Marcus, 2006).

9. Human equality: this term is referred to as a value and "implies that all human beings are equally entitled to just and respectful behavior, with consideration for their needs, and entitled to basic liberties such as thought and expression" (Deutsch, Coleman, \& Marcus, 2006).

10. Incivility: "involves acting rudely or discourteously, without regard for others, in violation of norms for respect in social interactions" (Andersson \& Pearson, 1999).

11. Interpersonal Conflict: this term is also known as dyadic conflict and refers to "conflict between two or more organizational members of the same or different hierarchical levels or units" (Rahim, 2011).

12. Intergroup Conflict: this term is also referred to as interdepartmental conflict and "refers to conflict between two or more units or groups within an organization" (Rahim, 2011).

13. Leadership: as referenced in this study, leadership is defined as "a subtle process of mutual influence fusing thought, feeling, and action. It produces cooperative effort in the service of purposes embraced by both leader and led" (Bolman \& Deal, 2008). 
14. Norms of cooperative behavior: the use of this phrase refers to other terms such as respectful, responsible, honest, empowering, and caring behavior toward fellow group members (Deutsch, Coleman, \& Marcus, 2006).

15. Organizational Conflict: this term refers to when the needs and goals of the organizations' individuals do not meet the needs and goals of the organization (Pierre \& Peppers, 1976).

16. Organizational Culture: "a pattern of shared basic assumptions learned by a group as it solved its problems of external adaptation and internal integration (Schein, 2010).

17. Reciprocity: this terms as it applies to conflict requires that people treat each other with fairness as if in the others' position or fairness to and from the other (Deutsch, Coleman, \& Marcus, 2006).

18. Shared community: "implicit in constructive conflict resolution is mutual recognition and being part of a broader community that members wish to preserve, a community sharing some key values and norms" (Deutsch, Coleman, \& Marcus, 2006).

19. Values: this term is defined as a level of organizational culture and can underlie and to an extent determine behavior. They are not directly observable and there may be a difference between stated and operational values (Schein, 2010).

The following chapters provide an examination and review of the selected literature used to support the basis for the study, the methods used in conducting the study, and a complete data analysis of the information gathered from the survey instruments: The Uncivil Workplace Behavior Questionnaire and the K \& C Organizational Culture Instrument. Finally, conclusions of the data analysis including recommendations for further research will be included. 


\section{Review of the Literature}

The contents of this chapter specifically addresses the nature of conflict and incivility; sources and dimensions of conflict; causes of conflict; and organizational culture and conflict. The content of this chapter further examines common connections between and among available research on these topics. It includes substantial insight into conflict and how unproductive workplace behaviors affect organizations, including institutions of higher education.

\section{The Nature of Conflict and Incivility}

The tenants associated with the nature of conflict as presented by the following researchers support mounting concerns for addressing uncivil behaviors in the workplace. These interactive, reactive, and proactive behaviors are becoming a priority for many organizations including higher education institutions. Pietersen (2005) contends that due to the increasing presence of certain types of uncivil behaviors in the workplace, there exists the potential for conflictive issues through decidedly physical assaults and organizational violence. These manifestations must be a serious focus for organizational leaders. Uncivil behavior affects interpersonal relations (Andersson \& Pearson, 1999), organizational departure, and organizational functioning (Pearson, Andersson, \& Porath, 2000). The prevalence of such contentious behaviors must be acknowledged and effectively resolved by leaders, not only within large corporations and organizations; but also within the context of institutions of higher education.

According to Penney and Spector (2005) counterproductive workplace behavior (CWB) is behavior by staff that could harm the entire organization and its members. Such behaviors may include but are not limited to uncivil actions such as: verbal abuse, lying, cooperative refusal, and then ultimately physical assault (Spector \& Fox, 2002). Andersson and Pearson 
(1999) argue that the social nature of incivility fosters unpleasant exchanges and can lead to more serious uncivil behaviors. Incivility has also been described by Andersson and Pearson as a spiral where uncivil acts of one lead to further acts of incivility by another. According to Penney and Spector (2005) incivility and CWB overlap but include and often exhibit different behaviors. Counterproductive workplace behaviors are typified as individual behaviors that have harmful intentions toward an individual person or the entire organization. In contrast, incivility is understood as behaviors that are not necessarily intentional but the meaning behind that harmful intent is discounted, undervalued, ignored, and often dismissed entirely. Andersson and Pearson (1999) conclude that uncivil behaviors are milder than CWB or they occur in more indirect or passive forms such as making derogatory remarks or ignoring someone. Counterproductive workplace behaviors and incivility are similar in terms of how they approach the social dynamic in which the uncivil behaviors occur (Penney \& Spector, 2005).

Studies completed by researchers Baron and Neuman (1998) emphasize the importance for being able to distinguish whether or not CWB is targeting the organization $(\mathrm{CWB}-\mathrm{O})$ or people (CWB-P) both of which are comprised of particular variables that have different relationships with each of the two categories (Penney \& Spector, 2005). One example of this theory is that injustice which is an organizational dimension is directly related to CWB-O, while conflict; considered as an interpersonal dimension, would be related to CWB-P (Fox, Spector, \& Miles, 2001). The research results support Andersson and Pearson's model of the incivility spiral effect, which is used to determine where the target of uncivil behavior is directed to the perceived agent. Therefore, the people who directly experience uncivil behavior are more likely to engage in CWB targeting individuals as opposed to the systemic human organizations. 
Andersson and Pearson (1999) contend that incivility in the workplace can function as a precursor to more aggressive acts, specifically, acts of physical assault. They also conclude that such acts of incivility have potential to spiral and increase to more intense and aggressive behaviors. While workplace interactions increase, there is greater opportunity and more ways to express disrespect and disregard to colleagues in the workplace (Carter, 1998; Marks, 1996). Results from several other studies conducted by Andersson and Pearson support the fact that uncivil behavior, aggression, and even violence occur in the workplace when they go unnoticed, underestimated, and then unresolved.

In 1993, the Northwestern National Life Insurance Company reported that almost 2.2 million workers in the United States had been victims of physical attacks and another 6.3 million had been verbally threatened, and 16.1 individuals reported that they had been harassed in the workplace (Anderson \& Pearson, 1999).

Romano (1994) conducted a study in organizations and found that over 20 percent of human resource managers experienced violence and aggression in the workplace within the past 20 years. There were an additional 33 percent of those managers who actually reported threats of violent acts within their organization.

The following model created by Andersson and Pearson (1999), describes their theory of the spiraling affects and reactions of incivility (see Figure 1). The spiral is to be interpreted and read from the bottom to the top of the figure. 
Figure 1. Sample Incivility Spiral

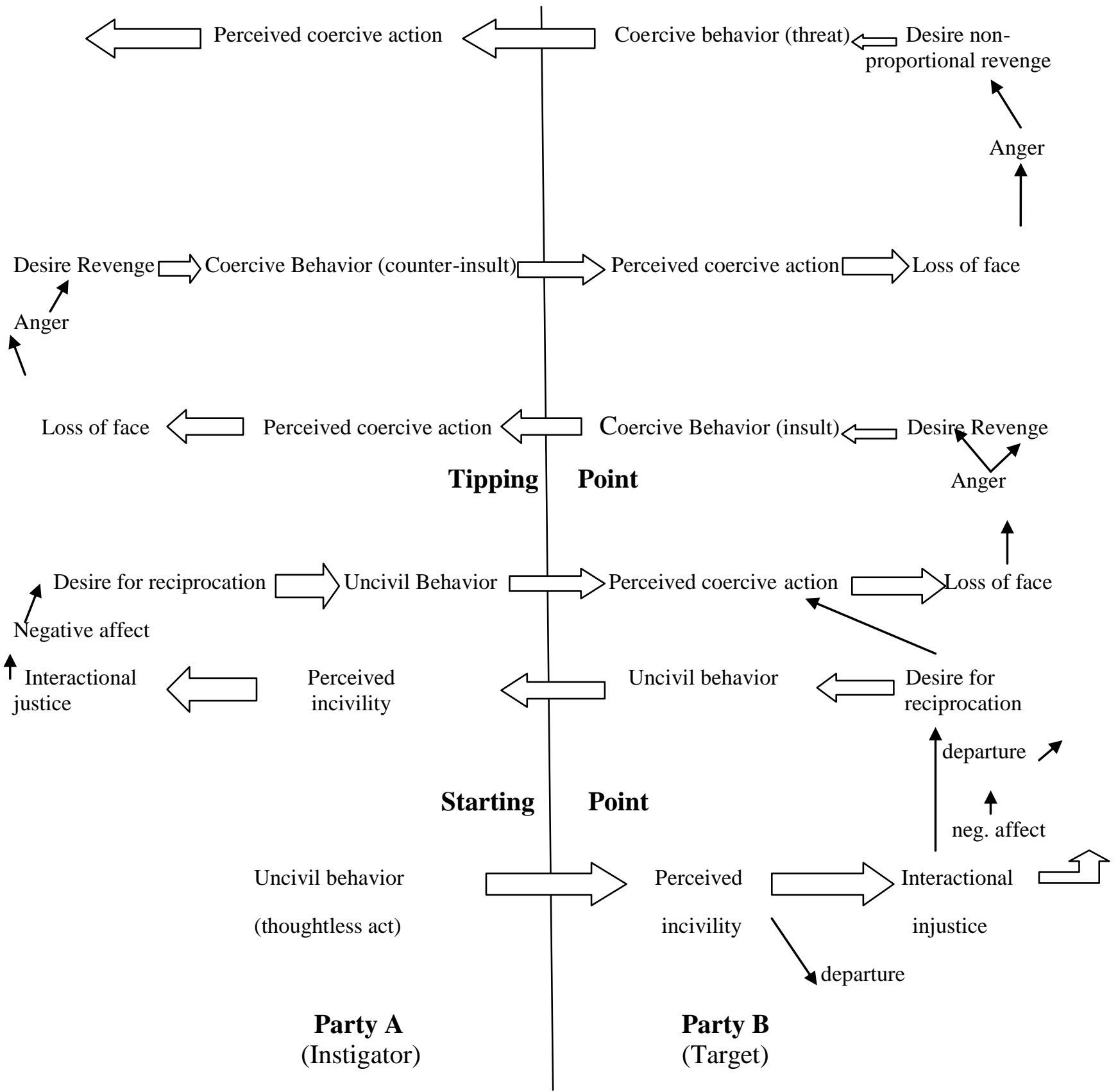

Figure 1. The Sample Incivility Spiral is used to depict the progression of uncivil behavior and should be interpreted from the bottom of the figure to the top. Adapted from "Tit for tat? The spiraling effect of incivility in the workplace, by L.M. Andersson \& C.M. Pearson, 1999, The Academy of Management Review, 24(3), p. 460. 
Collins (2009) provides additional support that conflict and uncivil behavior is inevitable in the workplace and though the type of conflict issues and experiences may vary from organization to organization therefore, it is the responsibility of leaders to manage it. Collins (2009) also contends that the most common reason that organizational conflict exists is because human beings are varyingly different. When people who are varyingly different are forced to work together, there is automatically an increased potential for personal conflict and disagreement over decision making and problem solving. Hence, uncivil behaviors are likely to occur within the organizational structure by mere virtue of the complexity of the human systems which comprise it.

Vega and Comer (2005) support the idea that workplace incivility not only is an increasing problem in the United States, but in other countries around the world. One example of another country paying considerable attention to the issue is the U.K. In 1997, the Andrea Adams Trust (ATT) was formed as one of the world's first non-political, non-profit organization that deals solely with the problem of uncivil workplace behavior. The organization has become so popular and increasingly supported, that several other organizations around the world have embraced the model in an effort to create a better understanding of incivility while providing resources for targets of uncivil behavior. Namie and Namie (2000) discovered that several union-based studies indicated that 66 percent of union employees either directly witnessed or were directly victimized themselves of uncivil actions within a six-month period.

According to Vega and Comer (2005) uncivil behaviors might include rude, foul, and abusive language, constant and unjustified criticism, assigning meaningless tasks to employees, humiliating conduct in front of co-workers, ridicule taunts, undermining someone's work 
performance, writing offensive e-mails, leaving offensive phone messages, and setting impossible deadlines.

This review of the literature examined the nature of conflict while clarifying the general schematic nature of conflict and incivility as it exists within organizations. For purposes stated in this study, it was relevant to present sources and dimensions of conflict developed by researchers who represent commonalities in their findings, theories, and perceptions of incivility in the workplace.

\section{Sources and Dimensions of Conflict}

The second section of the literature review describes the sources of conflict first and is followed with an examination of the dimensions of conflict. It is critical for leaders to have a clear understanding of the process of conflict in order to maximize productivity while decreasing destruction within the organizational setting (Fisher, 2000).

Senge (2006) views conflict in terms of structures (both implicit and explicit) within organizations. The first component of this framework is how the organizational structures influence organizational behaviors. When conflict occurs accompanied by inherent problems with noticeable decreases in performance levels within the organization, it is easier to project blame toward another possibly known culprit. Therefore, more often than not individuals realize it is the organizational system itself prompting crisis or conflict and not individuals or external mistakes. The second component of this framework relates to how human system structures are deceptively subtle creating ambiguities for resolving conflictive issues from within, as objectivity begins to diffuse once individuals become part of the culture within. Although many individuals think of structure as an external constraint; it can also mean how one's basic interrelationships can control behaviors as they relate to conflict. The third and final component 
of Senge's framework makes references to how it is individuals frequently try to use leverage within the organization's structure to promote new ways of thinking because they are solely focused on their own decisions and not how those decisions affect others.

While Senge sheds new light and perspective for how conflict can be recognized, it is also important to have an understanding for the various ways people think and perhaps how these thoughts affect productivity in learning organizations which assuredly includes institutions of higher education. According to Senge (2006), people become prisoners based on system exposure or prisoners of their own way of thinking. Therefore, individuals may be viewed by their peers as selfish as they do not comply with the norms of the organization. Senge (2006) suggests that individuals possess ideologies that may result in organizational conflict or dissonance due to the ideologies which the individual embraces and those espoused by the organization. First, individuals do not readily recognize how it is their actions affect the organization. Second, individuals often manifest mental habits for blaming others for nonproductive actions which promote tendency for making the situation worse through their actions. Third, individuals may not have the ability to recognize that their actions are creating incidence of conflict until it is too late or they have not learned from their previous actions that conflict was created. Finally, individuals can become so consumed in blaming others that they miss opportunity to learn from each other's experiences and realize that their issues within the organization are tied directly to the way they think.

Fisher (2000), advocates that conflict is not a result of a single component, but it is a mixture of several conflictive sources. Therefore, the more sources involved the more intense or escalated the conflict normally is. Conflict and incivility have the potential to escalate, becoming intense and often verbally hostile, creating more complex and compounding issues 
between the parties involved. Therefore, a pronounced escalation process is directly stimulated by fear and defensiveness.

Fisher (2000) also provides support that conflict occurs at different levels which include: interpersonal conflict that typically happens when two or more parties have incompatible goals, needs, and approaches whereas the breakdown of communication then becomes another source of the conflict. The next level of conflict is referred to as role conflict and involves differences between individuals' role definition and expectations or responsibilities. The third level involves intergroup conflict that occurs among small or large groups of people such as racial groups, departments, and management groups. Finally, the level of multi-party conflict refers to societies with different interest groups and organizations that set different priorities for management and policy development and often involve economic, value, and power as sources of conflict. While Fisher (2000) has provided some of the sources of conflict and levels at which conflict occurs, his framework also supports the work of Mertz and Lieber (2004) and their example of the five dimensions of conflict which is presented later in this literature review. Moreover, Kreitner (1980) provides further insight into organizational interpersonal conflict and determined that there are eight sources related to interpersonal conflict. These include ambiguous goals, competition for scarce resources such as departmental funding, communication breakdown between administrators and faculty, and time pressures which in higher education can be directly related to course overloads which faculty members are often forced to take. Another source of interpersonal conflict is the inconsistent standards initiated by administration such as faculty from one department having to teach the course overloads as opposed to other departments who administrators deem as more valuable to the institution, 
therefore they need to be readily available. The remaining sources include rules, policies or procedures, personality clashes, or unrealized expectations and incongruent roles.

Wall and Callister (1995) indicate that differences in individual and sub-unit goals can also serve as a source of conflict. Depending upon the complexity, magnitude, and temperament of certain issues within organizations, the more likely they will generate misunderstanding and encourage disagreement. In addition to Fisher (2000), these researchers provide yet more support of Mertz and Lieber (2004) and the five dimensions of conflict.

In 1995, Wall and Callister divided sources of conflict into three categories. The categories include individual characteristics, interpersonal factors, and issues. Studies have shown that different personalities encounter conflict more frequently than others and some societal values can determine a person's attitude toward conflict.

An example of how structure can be perceived as a source of conflict in higher education would be when administration determines that a major change needs to take place regarding curriculum within a specific department and creates a committee to re-structure the curriculum, when in fact, administration already has their plan charted. Most often, the end result is resentment from the faculty committee members chosen for the task and realization that administration had already made their decision. Now there is the existence of conflict between administration and faculty regarding how the structure of the institution truly functions. The notion of how structure plays a role and creates negative entropy within the institution is a trickle down affect or similarly, a trickle up affect as presented by Andersson and Pearson (1999) in their Incivility Spiral.

While researchers have provided in-depth information about sources of conflict, for the purposes of this study, the dimensions of conflict are parallel and one in the same therefore, are 
included in the review of the literature as a key component of incivility and conflict in the workplace. It is important to understand that if the attitudes leading to conflict can be mitigated and if psychology is the driving force of attitudes and behaviors of individuals and groups, then having a clear understanding of the social psychological dimension of conflict and its consequences is critical (Seymour, 2003). The first component of the social-psychological dimension is the history of the organization or institution. When groups interact with each other, patterns of the interaction will develop over time and the repeated experience will lead to the formation and solidification of the beliefs and perceptions of individuals and other group members. The next component of the social-psychological dimension refers to perceptions of individuals which also develop over a period of time and include values and threats from others, the distribution of power within the group, and control of resources between the group members. The third component of the social-psychological dimension is identity which refers to the norms, practices, and traditions of which group members engage into the environment. Identity provides a lens through which individuals view others and will form or change depending upon a particular moment (Seymour, 2003).

Seymour (2003) supports the idea of acknowledging the history of the organization, building awareness, learning empathy, and being able to recognize fears as powerful tools in building and sustaining peace within organizations and among groups.

According to Mayer (2000) conflict can be viewed through a three-dimensional perspective that includes cognitive (perception), emotional (feeling), and behavioral (action) dimensions. This perspective can help individuals clarify and have a better understanding of the complexities revolving around conflict and why it often proceeds in contradictory directions. 
Used as a set of perceptions, conflict is referred to as a belief that understanding others' needs, values, and wants are usually incompatible with someone else's, however both are objective and subjective components to the cognitive dimension. The emotional dimension of conflict is a feeling and a reaction to a situation or interaction that involves disagreement. The emotions can appear as sadness, fear, anger, or a combination of each. Consequently, the effect of one dimension can greatly affect the nature of the other two, depending upon the situation whereas each one of the three dimensions affects the others (Mayer, 2000).

Mayer (2000) continues the support of the three-dimensional perspective regarding conflict as action. The actions individuals take when expressing feelings articulate perceptions and have a way of meeting one's needs in such a way that there is potential for interfering with others' abilities to meet their individual needs. Conflict as action behavior might involve an attempt to make something happen at the other group members or individual's expense. The potential for conflict always exists between individuals that interact. Therefore, when considering conflict in the cognitive, emotional, and behavioral dimensions, one can see that conflict does not progress along one linear path. When individuals are dealing with different dynamics within the three dimensions, they behave and react accordingly which accounts for what appears to be irrational reactions to conflict and supports the model of Andersson and Pearson's Incivility Spiral while helping to identify actual causes of conflict.

Mertz and Lieber (2004) developed five dimensions of typical conflict whether it is interpersonal or global. Dimension one asks who or how many parties are involved and helps to determine whether the conflict is internal (conflict within oneself), interpersonal (conflict between two or more individuals), intra-group (conflict within a group which can be institutions, organizations, or groups of people who share specific roles or identities), or inter-group (conflict 
between two or more groups). Dimension two examines the source of the conflict and what may have precipitated the conflict. Examples may include conflict over resources, values, beliefs, perspectives, and psychological needs (power, control, and emotional). Dimension three determines the type of relationships between the conflicting parties and the level of intensity of the conflict and its potential outcome. This dimension also helps determine the climate that is present among the conflicting parties such as; trusting or suspicious, friendly or hostile, open or resistant, and calm or emotionally tense. Dimension four looks at the history of the conflict and the factors that might complicate conflict to include duration, frequency, intensity, and perception of the conflict by the parties involved. Finally, dimension five seeks to implement a process on how to deal with the conflict. The following figure was developed to illustrate how conflict can be traced from the initial parties involved to actually finding a solution for the situation (see Figure 2). 
Figure 2. The Five Dimensions of Conflict

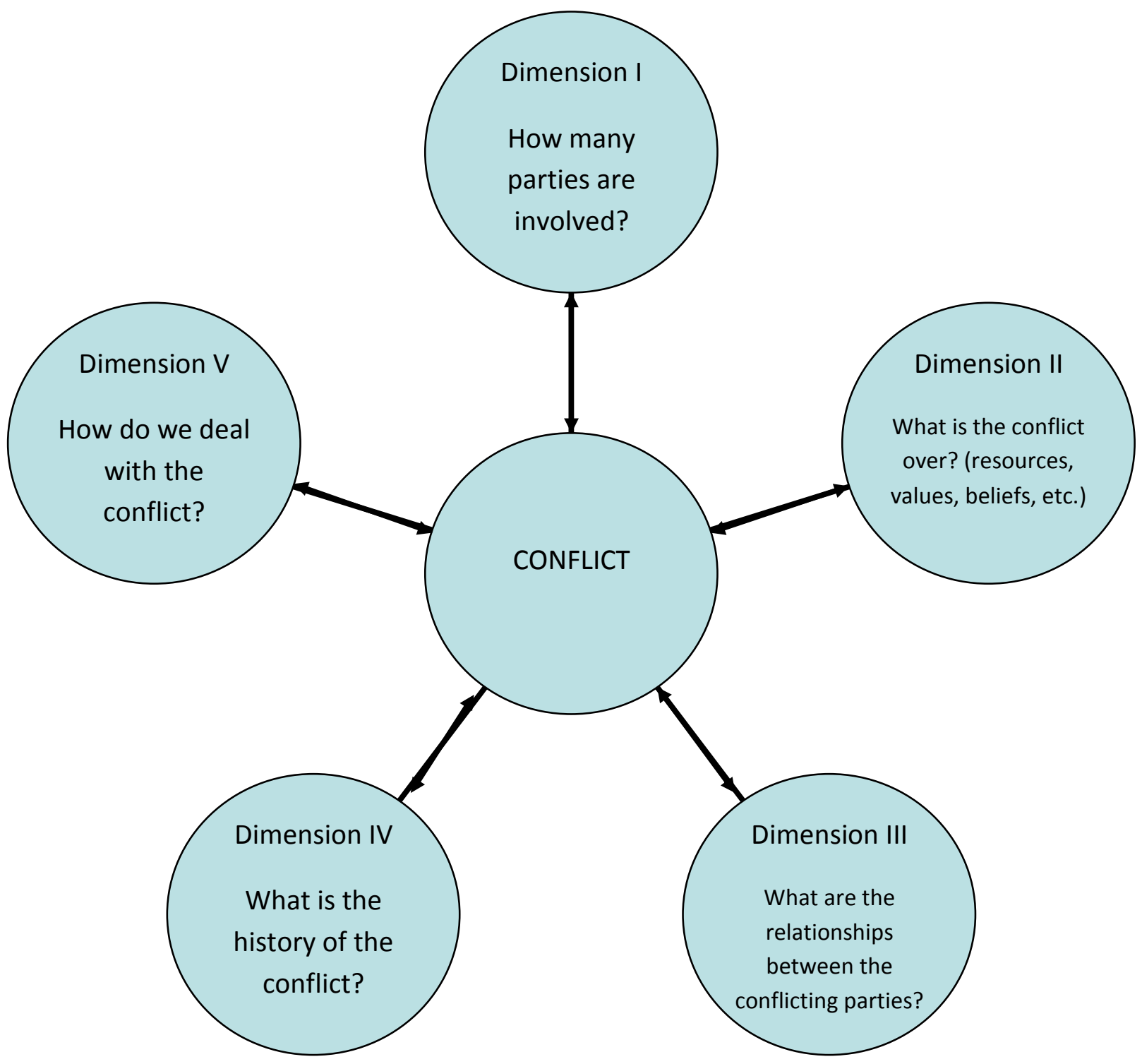

Figure 2. The information contained in this figure is a depiction of how conflict if related to each of the five dimensions. Adapted from "Five Dimensions of Conflict," by G. Mertz \& C. MillerLieber, 2004, Educators for Social Responsibility, 29, p. 4-6. 


\section{Causes of Conflict}

Continuing with the work of Mayer (2000) there are many roots to conflict, therefore several theories and frameworks have been developed in an effort to help define the origins of or actual causes of conflict. Mayer (2000) and Christopher Moore (1996) collectively, developed The Wheel of Conflict (see Figure 3) as a way to understand the causes of most conflicts. Because human needs are typically the center of all conflicts, it is the focal point of the wheel. Individuals engage in conflict often because their needs are either not met by the conflict process itself or because their needs are not consistent with the others in the group. Individual's needs are not the sole basis for conflict, there are several other forces that contribute to the process of conflict and include communication, emotions, values, structure, and history. The simple nature of the communication process enables individuals to be imperfect communicators, hence the imperfection causes conflict and often makes it almost impossible to resolve. Emotions also play a critical role in the wheel of conflict and are the primary source that fuels conflict. Because individuals are not always rational and focused on how to meet their own needs while accommodating the needs of others, conflicts among people would maybe never occur or quickly dissipate. The next force of the wheel of conflict involves values and beliefs regarding what individual's think are important while enforcing what is right or wrong, good or bad, and how individual principles guide lives. When values are integrated into conflict, the issue becomes personal, thus more difficult to resolve. Structure and history of the organization are also key forces within the wheel of conflict and may include resources, decision-making procedures, time constraints, communication processes, and physical settings (Mayer, 2000). 
Figure 3. The Wheel of Conflict

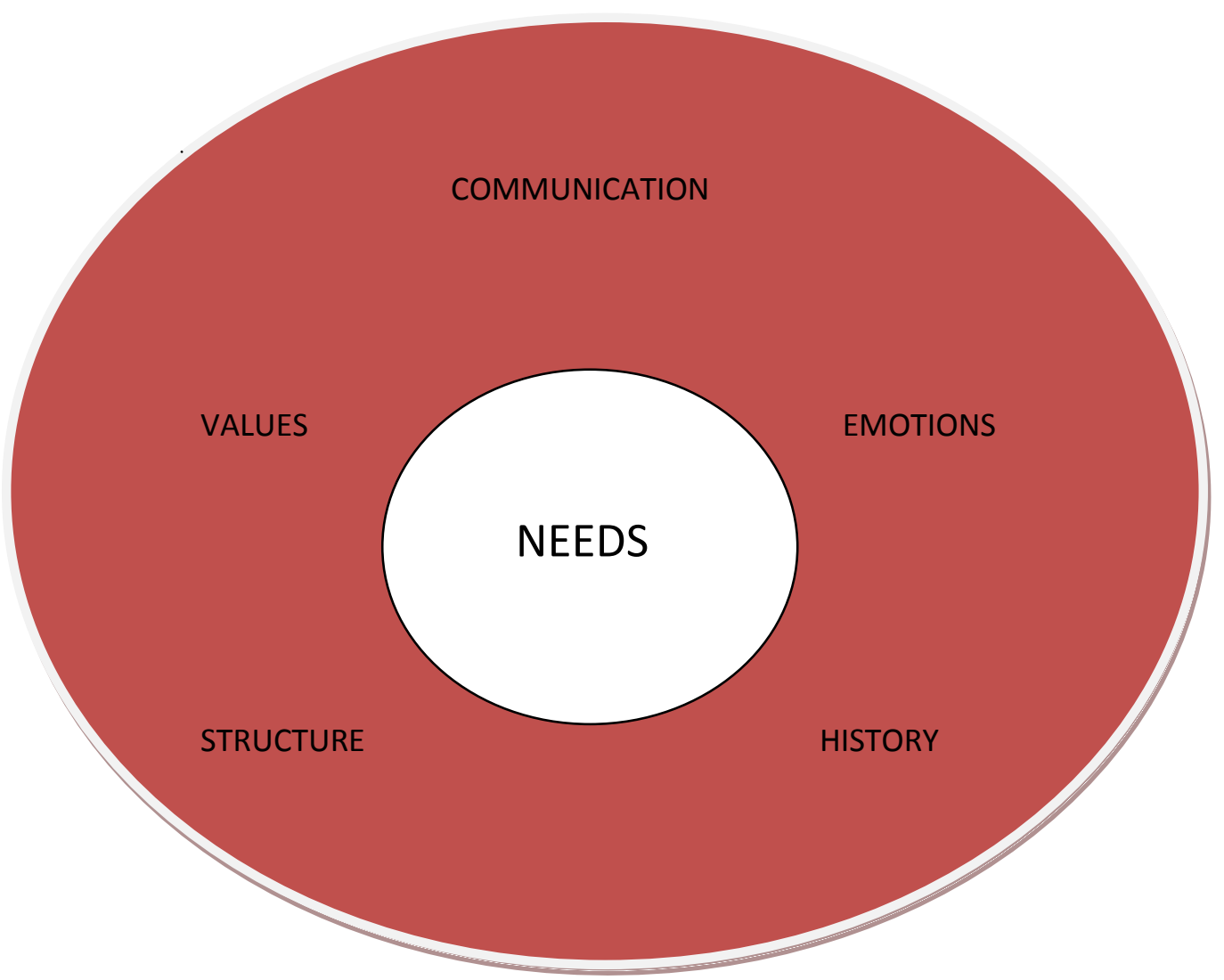

Figure 3. The figure of the Wheel of Conflict is being used to identify how human needs can be the nucleus for the onset of conflict and how these needs are related to individual and organizational culture. Adapted from "The Dynamics of Conflict Resolution: A Practitioner's Guide” by B.S. Mayer, 2000, p. 9. 
While many researchers have not specifically focused on finding real causes of conflict, empirical studies, theoretical pieces, and refined observations allowed them to specify or simply group the causes of conflict. Wall and Callister (1995) suggest several causes of conflict that include individual characteristics such as personality, values, goals, stress, and anger. Additional causes include interpersonal factors such as perceptual interface (other's intentions, other's behaviors seen as harmful, distrust, and misunderstanding), communication (insults, hostility, and dislikes), behavior (reduction of one's outcomes, blocking goals, and power struggles), and structure (closeness, status differences, preferential treatment, and symbols). Finally, previous interactions (past history of conflict, locked-in conflict behaviors, and past failure to reach agreement) and issues such as complex vs. simple, size, and vague vs. clear may also cause conflict.

Cortina, Magley, Williams, and Langhout (2001) conducted a study of interpersonal mistreatment using incidence, targets, instigators and the impact of incivility in the workplace. Results of data from 1,180 public employees collected, reported 71 percent of the participants experienced some type of incivility in their work environment within the past five years which supports the reasons why within the past ten years, so many researchers have focused their attention on many of the antisocial behaviors that result in conflict. These behaviors include aggression, harassment, bullying, deviance, and even violence. Therefore, with the increased interest and incidence of uncivil behavior in the workplace, researchers Griffin, O'Leary-Kelly, and Collins (1998) have focused attention as well on the physical, active, and direct forms of aggression.

Forni (2008) also supports the notion that rudeness or incivility causes stress, erodes selfesteem, creates issues in relationships, makes the workplace environment difficult, and can 
escalate to severe violence. Data results from a study conducted by Pearson and Porath (2005) report 90 percent of workers in the U.S. indicate that they have experienced uncivil workplace behavior and that 13 percent of those workers left their organization. Additionally, four out of the ten of the study participants reported having worked for an abusive employer or manager. Therefore, current leaders are spending 18 percent of the work week diffusing uncivil behavior and conflict which works out to be almost one entire work day per week (Forni, 2008).

In a study conducted by Pearson, Andersson, and Porath (2000) their results from a large range of participants indicate that one cause of workplace incivility is the technological advances of the new millennium has been a cause of workplace incivility due, in part, to the impersonal aspect of voice-mail, e-mail, and teleconferencing. Technology facilitates opportunity for humans to avoid face to face contact and communication, thus creating a potential environment for conflict to occur. Similar participant responses indicated that the overload of work and information creates feelings of time pressure and less time to be civil to co-workers (Pearson, Andersson, \& Porath, 2000). Several other study participants contend that organizational downsizing, budget cuts, and pressure for increased productivity act as facilitators in creating uncivil behavior in the workplace. Societal shifts have also played a role in opportunity for uncivil behaviors to occur and that the media, ineffective primary and secondary education, and lack of parental involvement can act as hosts for incivility.

According to Pierre and Peppers (1976) one cause for the rise in uncivil behavior in the workplace is due to societal components such as values and beliefs which create incidences about what is right and wrong behavior. Motivation, ideals, and philosophies are also causes of conflict because individuals often use these as a basis for their behavior. Hornstein (2003) suggests that it is leaders in organizations who cause conflict. Status and power taken advantage 
of by many organizational and institutional leaders, creates a high level of temptation to use incivility as a way of engaging others in the behavior. Such leaders are attempting to create an environment of me and we which can create barriers among employees in the organization and facilitate opportunity for incivility and conflict. The result of this type of barrier creation by leaders is simply that the organization or institution ends up being the loser and not the individuals.

Glomb and Liao (2003) dovetailed their study of interpersonal aggression, social influence of uncivil behaviors, reciprocal, and individual influence on workplace aggression based on the work of Robinson and O'Leary-Kelly (1998) whose findings suggest that uncivil or anti-social behaviors of a group of individuals influences the behaviors of other individual employees. Researchers have supported the notion that aggression and uncivil behavior is reciprocal in nature. For example, if one person engages in uncivil behavior toward another, it is highly likely that they, in turn will become the target of the original person of which they demonstrated uncivil behavior toward (Glomb \& Liao, 2003). Other factors influencing uncivil behavior in the workplace include individual differences and characteristics. Some of these individual characteristics include hostile attribution bias or individual hostile intentions toward others; type A behavior pattern, anger, lack of self-monitoring, and personal history of aggression (Chen \& Spector, 1992; Baron \& Neuman, 1998).

The causes of conflict are well noted by the researchers previously cited. While this portion of the review of the literature has extended the knowledge base on causes for uncivil behavior and conflict, it is important to gain a further understanding of how cultural forces might allow people to better understand themselves and not become victims to those forces (Schein, 2010). 


\section{Organizational Culture and Conflict}

According to Schein (2010), organizational culture is seen as an abstraction and the forces created within the social and organizational structures which can be powerful because they occur outside of one's awareness. The need to understand these forces is not only due to their power, but also to help explain the frustrating behaviors and experiences which occur in social and organizational life. While understanding the concept of culture and the phenomena which surround it is important, it is also equally important to understand the dynamics of culture. Understanding the dynamics of culture in an organization can help people become less irritated and puzzled when they encounter irrational behaviors of the people within their organization (Schein, 2010). Organizational culture is also defined according to its artifacts or history of the organization, espoused values and beliefs of the people within the organization, and basic assumptions on which the organization is based. Therefore, espoused values and beliefs in academic practices should align nicely with the daily practices in higher education (Schein, 2010).

Goffman (1959) identifies culture as a friendly, cooperative and presentable appearance. However, the part of the culture that is not seen can be ambiguous, cluttered, and hidden from view on purpose. This concept effectively describes the culture of academe whereas institutional missions and philosophies help shape academic culture. The reality of culture in higher education is that faculty and administrators have egos, hidden agendas, make deals, ideological conflicts, and personality and power struggles; some of which are visible on the surface but can be dormant and hidden from view, and at any moment, ready to explode (Seldin, 1984).

Somers, et al. (1998) refer to culture in higher education as the campus climate. With the rapidly changing climate of institutions of higher education, faculty and administrators act as 
weather radar and can see the storm clouds approaching while preparing for the major storm of accountability, monsoon of tenure review, a tornado of diversity, a typhoon of unprepared students, and thunderstorms full of financial difficulties.

Schein (2010) also suggests that culture is an empirically based abstraction and that many researchers and organizational leaders use culture to define the norms and practices which organizations develop over time in an effort to handle people, their espoused values, and the organization. The concept of culture may also dictate the climate of an organization perhaps confusing culture with what is as opposed to what ought to be in an organization. Much of the managerial literature implies that creating a culture is necessary for organizations to perform effectively thus, having a strong positive culture encourages higher performance levels within the organizations (Schein, 2010).

There are several models of observable behaviors and forces by which the concept of culture can be built upon. Some of these models include observed behavioral regularities such as language or customs used when people interact, group norms, espoused values or principles the group is using, rules of organization or game, climate of the organization, habits of thinking, mental models and paradigms, shared meanings within the organization, and formal rituals or celebrations (Schein, 2010). The cultural concept might also define organizational stability, depth of culture, breadth of culture within the organization, and how culture is integrated into organizations.

Bohlman and Deal (2008) suggest that organizational culture is symbolic and is applicable to both groups and teams within an organization. The culture can be defined by one or more of the following components: the importance of how an individual becomes a group member, diversity within the organization, leading by example and not command, encouraging 
specific language that fosters cohesion and commitment to the organization, organization stories, history and values, encouragement of creativity, and organizational ritual and ceremonies typically carried out as expressive occasions.

According to Kimmel (1995), if situations of conflict are bilateral or multilateral, technical or ideological, or the standard for success is victory or solving the problem, then regardless of the organizational culture, communication is a key factor. Thus, understanding basic cultures and their differences and creating communalities can facilitate communication and guide the problem solving process. Kimmel also uses the term micro-cultures when referring to common meanings, norms of communication, behaviors of individuals, perceptions and expectations, and the roles and relationships that build over time between people in organizations. Hence, the probability of misunderstandings and breakdowns in communication are inevitable.

Cultures have historically been defined by humans according to what is important to those who share the same values and beliefs. They can be organic, whole, or dynamic in nature therefore, cultures are learned through socialization and the growing up process (Kimmel, 1995). To further understand culture and cultural awareness, Triandis (1989) suggests that learned shared perceptions or what is often referred to as subjective culture or mindsets are actually plans and rules individuals embrace to interpret their environment and act accordingly within it.

Cultural identity can have a significant effect on how individuals communicate with one another. When identifying culture and conflict, it is important to recognize that the negotiation process among individuals in a group setting can be daunting and often result in highly uncomfortable situations. 
Kefela (2010) views organizational culture as a basic system of beliefs, values, and norms by which individuals within the organization or institution embrace, therefore helps determine how individuals respond when faced with decision-making opportunities. Culture within institutions of higher education as well as other organizations can be created through the institution's ideologies, legends, past heroes, stories, and rituals. Culture becomes a key component of the institution leaders' efforts to achieve the institution's goals and mission, while improving organizational effectiveness (Kefela, 2010).

Twale and DeLuca (2008) have studied culture more specifically as it relates to higher education. They suggest that individuals coming into the new culture have to be accepted by current faculty and administrators while embracing the values, beliefs, ideologies, laws, and policies which govern that culture.

Tierney (1988) suggests that leaders in higher education should continue to ask themselves questions such as what is holding the institution together and what are the responsibilities of the leaders within. Institutions in higher education of similar size, mission, values, and curricula will perform differently based on their identities and the different perceptions the groups hold. They are also shaped by power, internal and external forces, and economic and political influences. These dynamics are often rooted in the history of the institution and have developed through values, beliefs, processes, and goals of the individuals involved (see Table 1). 
Table 1

A Framework of Organizational Culture

\begin{tabular}{|c|c|c|c|}
\hline Environment & $\begin{array}{l}\text { How does the } \\
\text { organization define } \\
\text { its environment? }\end{array}$ & $\begin{array}{l}\text { What is the attitude } \\
\text { towards the } \\
\text { environment? } \\
\text { (Hostility or } \\
\text { Friendly) }\end{array}$ & \\
\hline Mission & $\begin{array}{l}\text { How is it defined? } \\
\text { How is it articulated? }\end{array}$ & $\begin{array}{l}\text { Is it used as a basis } \\
\text { for decisions? }\end{array}$ & $\begin{array}{l}\text { How much } \\
\text { agreement is } \\
\text { there? }\end{array}$ \\
\hline Socialization & $\begin{array}{l}\text { How do new } \\
\text { members become } \\
\text { socialized? }\end{array}$ & How is it articulated? & $\begin{array}{l}\text { What do we need } \\
\text { to know to } \\
\text { survive in the } \\
\text { organization? }\end{array}$ \\
\hline Information & $\begin{array}{l}\text { What constitutes } \\
\text { information? }\end{array}$ & Who has it? & $\begin{array}{l}\text { How is it } \\
\text { disseminated? }\end{array}$ \\
\hline Strategy & $\begin{array}{l}\text { How are decisions } \\
\text { arrived at? }\end{array}$ & $\begin{array}{l}\text { Which strategy is } \\
\text { used? }\end{array}$ & $\begin{array}{l}\text { Who makes } \\
\text { decisions? }\end{array}$ \\
\hline Leadership & $\begin{array}{l}\text { What does the } \\
\text { organization expect } \\
\text { from its leaders? }\end{array}$ & Who are the leaders? & $\begin{array}{l}\text { Are there formal } \\
\text { and informal } \\
\text { leaders? }\end{array}$ \\
\hline
\end{tabular}

Note: A Framework of Organizational Culture. Adapted from Tierney, W.G. (1988).

Organizational culture in higher education: defining the essentials. The Journal of Higher

Education, 59(1), 2-21. 


\section{Summary of the Literature Review}

The examination of the selected literature was reviewed and divided selectively into five categories specifically related to incivility and conflict in higher education and how perceptions of conflict and incivility might differ between administrators and faculty members. The first category examines The Nature of Conflict and Incivility in organizations. This component of the literature review was used as a major building block and reference point for the basis of this study. The works of Penney and Spector (2005) on Counterproductive Workplace Behavior (CWB) and the relationship to the work of Andersson and Pearson (1999) with their Incivility Spiral Sample were used as a framework for this study. To support these theories, other researchers are included in the literature who conducted empirical research further defining whether CWB is targeted toward the organization (CWB-O) or only to one person (CWB-P) within an organization.

The second relevant component of the reviewed literature describes specific sources of conflict and how these sources impact the levels of conflict within organizations and institutions of higher education. Some of the sources of conflict include structure within an organization, how people think as it relates to and creates conflict, interpersonal components of conflict such as communication breakdown and misinterpretation of others behaviors, and how perceptions of conflict can act as a source of conflict. Further review of the selected literature within this component examined the dimensions of conflict and includes the works of Mayer (2000) and the three-dimensional perspective of conflict; and more specifically, the five dimensions of conflict developed by Mertz and Lieber (2004).

The next component of the literature review examined the many roots of conflict and includes several researchers' theories and frameworks that have been developed in an effort to 
better define origins and causes of conflict. The development of the Wheel of Conflict created by Moore (2000) was modified and included in the literature review as another visual source of reference. The fourth component of review of the literature examined organizational culture as it relates to conflict in organizations and higher education. The more current research and supporting literature conducted by Schein (2010) and Kefela (2010) was included and further defined organizational culture and how it affects organizations and institutions of higher education. 


\section{Research Method}

The contents of this chapter outlines and defines the specific methodology that was used in researching and examining the differences between administrator and faculty member's perceptions of incivility in higher education. This chapter also outlines the methodology which was used to identify possible correlations between incivility and organizational culture based upon administrator and faculty member's perceptions of organizational culture. The chapter outlines the design of the study, the participants used in the study, the specific instruments used for the collection of the data, considerations and concerns of the administration of the questionnaires, and the data analysis strategies.

\section{The Study Design}

This quantitative research was designed to be a correlation study between administrators and faculty members regarding their perceptions of incivility within their particular institution of higher education. The study was aimed at not only examining the differences of perception of incivility in the workplace between administrators and faculty members, but to also extend the knowledge of the phenomenon of incivility and conflict within institutions of higher education. Data were gathered as a result of the administration of a combination of two instruments: (1) The Uncivil Workplace Behavior Questionnaire (Martin \& Hine, 2005) and (2) The K \& C Organizational Culture Instrument (Kendig \& Chapman, 2012).

\section{Research Questions}

The following research questions were developed to guide the study which examined the perceptions between administrators and faculty members of incivility and conflict, and institutional culture in higher education. Moreover, a third research question was developed to examine the correlation between incivility/conflict and organizational culture. 
RQ 1. Do administrators and faculty members perceive incivility/conflict differently?

$H$ There is a statistically significant difference in perceptions of incivility and conflict between administrators and faculty members.

$H_{\text {。 }}$ There is no statistically significant difference in perceptions of incivility/conflict between administrators and faculty members.

RQ 2. Do administrators and faculty members perceive organizational culture differently?

$H$ There is a statistically significant difference in perceptions of organizational culture between administrators and faculty members.

$H$ 。 There is no statistically significant difference in the perception of organizational culture between administrators and faculty members.

RQ 3. Are there relationships between the institution's perceived culture and perceptions of incivility/conflict?

$H$ There are statistically significant relationships between institutional culture and perceptions of incivility.

$H_{\circ}$ There is no statistically significant relationship between institutional culture and perceptions of incivility.

\section{Participants of the Study}

The participants of the study were recruited from three institutions of higher education, all of which are classified as four-year public institutions, primarily baccalaureate with some master's programs, and a balanced arts \& sciences undergraduate instructional program (Carnegie Classification, 2010). The three institutions of higher education have been selectively chosen based upon student population and similarities in total numbers of administrators and faculty. Two of the institutions have similar student populations of 8,878 and 8,253 with the third 
having a smaller student population of 4,256 . The size and setting of all three institutions is classified as medium, four-year and primarily residential (Carnegie Classification, 2010).

Institution one is a four-year public institution with a current enrollment of 8,878 students. This institution has a profile classification of an undergraduate instructional program that includes balanced arts and sciences/professions and some graduate coexistence. Institution one also has a classification profile which includes a graduate instructional program with postbaccalaureate of arts and sciences with education being the dominant discipline. There is a very high undergraduate enrollment profile with an undergraduate profile of full-time four-year, selective, and a higher transfer-in rate. Institution one has 116 full time decision making administrators and 352 faculty members working in the full time, visiting, and part time or adjunct capacities.

Institution two is also a four-year public institution with an enrollment of 8,253 students. This institution is classified as an undergraduate instructional program with balanced arts and sciences/professions and some graduate coexistence. The graduate instructional program at this institution is a comprehensive post-baccalaureate program with a very high undergraduate enrollment profile. The undergraduate profile is classified as full-time four-year with selective programs and a higher transfer-in rate. Institution two has 55 administrative decision making staff and 340 faculty members working in the full time, visiting, and part time or adjunct capacities.

Institution three, the smallest of the institutions is also classified as a four-year public institution with a current enrollment of 4,256 students. The undergraduate instructional program at institution three includes balanced arts and sciences/professions and some graduate coexistence. The graduate instructional program at institution three is post-baccalaureate 
professional with education being the dominant program. Institution three has a very high undergraduate enrollment profile and an undergraduate profile of full-time four year students and higher transfer-in rate. Institution three currently employs 77 executive, administrative, and managerial staff, also at the decision making level as well as 364 faculty members working in the full time, visiting, and part time or adjunct capacities (see Table 2).

Table 2

Participants of the study

\begin{tabular}{lcc}
\hline Institution & Administrators & Faculty Members \\
\hline One & 116 & 352 \\
Two & 55 & 340 \\
Three & 77 & 364 \\
Total & 248 & 1056 \\
\hline
\end{tabular}

\section{Instrumentation}

The study was conducted using two different survey instruments. The first was the Uncivil Workplace Behavior Questionnaire developed by Martin and Hine, 2005 (see Appendix A). This instrument measures uncivil acts of behavior such as (1) hostility, (2) privacy invasion, (3) exclusionary behavior, and (4) gossiping. The instrument in its current format has 20 items with a five point Likert-type scale answer series with choices of never, rarely, occasionally, often, and very often. The Uncivil Workplace Behavior Questionnaire is one of only two selfreport constructs ever developed to measure workplace incivility and for the purposes of this study will be useful in drawing conclusions regarding perceptions of administrators and faculty members of incivility and conflict in their higher education environments. The Uncivil Workplace Behavior Questionnaire demonstrates good convergent validity that ranges from .28 to .65. The researcher was granted written permission by the authors of the Uncivil Workplace 
Behavior Questionnaire (Martin \& Hine, 2005) to use or modify the instrument as the researcher saw fit for this particular study (see Appendix C).

The Uncivil Workplace Behavior Questionnaire was constructed by using a four factor pattern: Factor 1: Hostility, Factor 2: Privacy Invasion, Factor 3: Exclusionary Behavior and Factor 4: Gossiping. There are four items included in factor one of which there is a score range of four to 20. Factor two has a score range of five to 25 and includes five items while factor three has a score range of seven to 35 and includes seven items. Factor four has four items which also has a score range of four to 20. The total composite ranges from a possible score of 20 to 100 .

The second instrument to be used is the K \& C Organizational Culture Instrument (see Appendix B), developed by the researcher and committee chair. This instrument aimed at drawing conclusions about perceptions of organizational culture between administrators and faculty members. This instrument uses a four point Likert-type scale with the answer options of strongly agree, agree, disagree, and strongly disagree. The instrument is a 12 item construct and has been designed based upon organizational culture and the works of Schein (2010) and the organizational framework developed by Tierney (1988). The instrument is a three factor construct with each factor containing four items. The first factor of statements focuses on institutional history, artifacts and environment. The second factor of the instrument focuses on espoused values, beliefs, and mission, while the third factor has been developed around the concept of basic assumptions and institutional leadership. All three factors have a possible scoring range of four to12 with an overall possible composite score of 12 to 36 . 


\section{Data Collection}

The process of data collection required the researcher to create a master e-mail list of the 248 administrators and 1,056 faculty members within each of the three institutions participating in this study.

Participants chosen for this particular study were contacted via e-mail requesting acceptance to participate in the study (see Appendix' D \& F). Formal cover letters were attached to the e-mails outlining the purpose of the study, goals and objectives of the study, and a statement of confidentiality for each participant. Participants were confidentially protected within the Qualtrics survey program to insure identity protection and anonymity.

There were two instruments used for this study. The first instrument used is the Counterproductive Workplace Behavior Questionnaire (Martin \& Hine, 2005). The second instrument to be used is the $\mathrm{K}$ and $\mathrm{C}$ Organizational Culture Instrument. The survey was created by combining the content of both instruments and using The Qualtrics survey system and administered to the chosen population of administrators and faculty members. The study was approved by the West Virginia University Institutional Review Board for Protection of Human Subjects. The study was also approved by the Institutional Review Boards operating within each of the three institutions.

\section{Analysis of the Data}

This chapter also provides a detailed description or the types of analysis used to answer the three research questions based on the scores of the survey instrument Organizational Culture and Uncivil Workplace Behavior. The use of descriptive statistics were relevant to this study as they measured mean, standard deviation, and allowed the researcher to compare the differences 
between the two groups (administrators and faculty members) or measure the standard score (Field, 2005).

To answer research question one; Do administrators and faculty members perceive incivility/conflict differently? The Uncivil Workplace Behavior Questionnaire was used. There was one $t$-test computed for factor one: hostility, one $t$-test computed for factor two: privacy invasion, one $t$-test computed for factor three: exclusionary behavior, and one $t$-test computed for factor four: gossiping. A fifth $t$-test was computed to examine the overall composite score.

To answer research question two; Do administrators and faculty members perceive organizational culture differently? The K \& C Organizational Culture Instrument was used. There was one $t$-test computed for factor one: artifacts/history/environment, one $t$-test computed for factor two: espoused values/beliefs/mission, and one $t$-test computed for factor three: assumptions/leadership. The fourth $t$-test was computed to examine the overall composite score of the instrument.

To answer research question three; Are there relationships between the institution's perceived culture and incivility/conflict? Pearson's $r$ Correlation Coefficient Matrix was used to measure the degree of correlation between organizational culture and incivility/conflict.

The correlation matrix analysis was used to measure relationships between the dependent variables (factors) and the independent variable (administrators and faculty). The number or correlation coefficients range from -1.0 to +1.0 determining the degree to which the variables are related. The correlation matrix was used to examine and measure different relationships and assist the researcher with drawing conclusions from the analysis on the differences of perceptions of incivility and organizational culture in higher education. 


\section{Summary of the Methodology}

The contents of this chapter outlined the methods (a) $t$-tests and (b) correlation matrix, used to conduct the study. The chapter also provides information pertaining to the specific design of the study (a quantitative analysis) and a detailed description of the participants chosen for the study. The instruments used in the study included the Uncivil Workplace Behavior Questionnaire (Martin \& Hine, 2005) (UWBQ) and the K \& C Organizational Culture Instrument (K \& C-OCI). Details have been provided that outline the data collection process, and data analysis procedure. 


\section{Results and Data Analysis}

The findings and analysis of Uncivil Workplace Behavior and Organizational Culture are presented in this chapter based upon the data collected from this sample of administrators and faculty members in higher education. Moreover, the content of this chapter addresses the following research questions:

RQ1. Do administrators and faculty members perceive incivility/conflict differently?

RQ2. Do administrators and faculty members perceive organizational culture differently?

RQ3. Are there relationships between the institution's perceived culture and incivility/conflict?

Two instruments were combined in a survey and used in this study. The first instrument to be used was the UWBQ developed by Martin \& Hine (2005) and was aimed at gaining information regarding perceptions of incivility/conflict between administrators and faculty members in this sample (see Appendix A). This instrument consists of 20 items and is divided into four different factors: (a) hostility with four items, (b) privacy invasion with five items, (c) exclusionary behavior with seven items, and (d) gossiping with four items.

The second instrument used was the $\mathrm{K} \& \mathrm{C}$-OCI developed by the researcher and dissertation committee chair and was aimed at drawing conclusions on perceptions of organizational culture between administrators and faculty members (see Appendix B). This instrument consists of 12 items and was developed based upon organizational culture and the works of Schein (2010) and the organizational framework developed by Tierney (1988). The instrument is a three factor construct with each factor containing four items: (a) organizational history and environment, (b) organizational mission, and (c) organizational leadership. 


\section{Survey Responses and Demographic Information}

The sample for this study included 248 administrators and 1056 faculty members. From the overall sample, 219 responded with $n=185$ of those respondents completing the survey in its entirety. Those respondents who completed the survey included 34 administrators holding positions at the dean and executive decision making levels, yielding an overall response rate of $13 \%$ and 151 faculty members holding professional positions as part-time or adjunct, full-time non-tenured, and full-time tenured faculty positions, yielding a response rate of $14 \%$. The respondents at the administrative or executive decision making level totaled $13 \%$ while the response rate of Dean's totaled 5\%. The response rate of faculty members included $42 \%$ fulltime tenured faculty members, $28 \%$ full-time non-tenured faculty members, and $1 \%$ visiting faculty members. The part-time or adjunct faculty member response rate yielded $11 \%$ of the total responses (see Table 3).

Table 3

Professional status of respondents

\begin{tabular}{l|c}
\hline \multicolumn{1}{c|}{ Professional Status } & Response Rate \\
\hline Administrator/Executive Level decision maker & $13 \%$ \\
Deans & $5 \%$ \\
Full-time Tenured Faculty Member & $42 \%$ \\
Full-time Non-Tenured Faculty Member & $28 \%$ \\
Visiting Faculty Member & $1 \%$ \\
Part-time/Adjunct Faculty Member & $11 \%$ \\
\hline
\end{tabular}


The original letter of request for participation was sent electronically on June 28, 2012 with a reminder request for participation sent on July 30, 2012. The responses were low; hence another reminder for participation in the study was sent electronically on August, 10, 2012. The low response rate became a critical concern for this study therefore; a final request for participation was sent electronically again on September 4, 2012 in an effort to increase the overall response rate. Low response rates are common with the electronic survey method (Sills \& Song, 2002).

\section{Statistical Analysis of the Data}

The UWBQ (Martin \& Hine, 2005), consists of 20 five point Likert-type scale items that include the respondents' perceptions of (a) hostility, (b) privacy invasion, (c) exclusionary behavior, and (d) gossiping as these factors relate to their everyday work environment. Item responses range from one (never) to five (very often). Scores for (a) hostility range from four to 20, (b) privacy invasion five to 25, (c) exclusionary behavior seven to 35, and (d) gossiping four to 20. The overall composite score range for the UWBQ is 20 to 100 (see Table 4).

Table 4

UWBQ Factors and Score Range

\section{Factor}

Hostility

Privacy Invasion

Exclusionary Behavior

Gossiping

Overall Composite
Score Range

4 to 20
5 to 25
7 to 35
4 to 20
20 to 100


The hostility factor includes items one, a colleague raised their voice while speaking to you. Two, a colleague used an inappropriate tone when speaking to you. Three, a colleague spoke to you in an aggressive tone of voice, and four, a colleague rolled their eyes at you. The privacy invasion factor includes items one, a colleague took office materials from your desk without later returning them. Two, a colleague took items from your desk without prior permission. Three, a colleague interrupted you while you were speaking on the phone. Four, a colleague read communications addressed to you, such as e-mails or faxes, and five, a colleague opened your desk drawers without your permission. The exclusionary behavior factor consists of items one, a colleague did not consult you in reference to a decision you should have been involved in. Two, a colleague gave unreasonably short notice when cancelling or scheduling events you were required to be present for. Three, a colleague failed to inform you of a meeting you should have been informed about. Four, a colleague avoided consulting you when they would normally be expected to do so. Five, a colleague was excessively slow in returning your phone message or e-mail. Six, a colleague intentionally failed to pass on information which you should have been made aware of. The last item reads; a colleague was unreasonably slow in seeing to matters on which you were reliant on them for without good reason. The gossiping factor, includes items one, a colleague publicly discussed your confidential personal information. Two, a colleague made snide remarks about you. Three, a colleague talked about you behind your back, and four, a colleague gossiped behind your back (see Table 5). 
Table 5

UWBQ Factor Items

\section{Item}

\section{Factor 1: Hostility}

Raised their voice while speaking to you

Used an inappropriate tone when speaking to you

Spoke to you in an aggressive tone of voice

Rolled their eyes at you

\section{Factor 2: Privacy Invasion}

Took office materials from your desk without later returning them

Took items from your desk without permission

Interrupted you while you were speaking on the phone

Read communications addressed to you, such as e-mails and faxes

Opened your desk drawers without your permission

\section{Factor 3: Exclusionary Behavior}

Did not consult you in reference to a decision you should have been involved in

Gave unreasonably short notice when cancelling or scheduling events you were required to be at

Failed to inform you of a meeting you should have been informed about

Avoided consulting you when they would normally be expected to do so

Was excessively slow in returning your phone message or e-mail

Intentionally failed to pass on information which you should have been made aware of

Unreasonably slow in seeing to matters on which you were reliant on them for without reason

\section{Factor 4: Gossiping}

Publicly discussed your confidential personal information

Made snide remarks about you

Talked about you behind your back

Gossiped behind your back

Note: Adapted from "Development and Validation of the Uncivil Workplace Behavior Questionnaire" by R.J. Martin and D.W. Hine, 2005, Journal of Occupational Health Psychology, 10, No. 4. 
The K \& C-OCI consists of 12 four point Likert-type scale items consisting of respondents' perceptions of (a) organizational history and environment with four items, (b) organizational mission with four items, and (c) organizational leadership also with four items. Item responses range from one (strongly agree) to four (strongly disagree). All three factors have a scoring range of four to 12 . The overall composite score range for the $\mathrm{K} \& \mathrm{C}$-OCI is 12 to 36 (see Table 6).

Table 6

K \& C-OCI Factors and Score Range

Factor Score Range

\begin{tabular}{lc}
\hline Organizational History and Environment & 4 to 12 \\
Organizational Mission & 4 to 12 \\
Organizational Leadership & 4 to 12 \\
Overall Composite & 12 to 36 \\
\hline
\end{tabular}

The organizational history and environment factor includes items one, my work environment has the tendency to be hostile. Two, I consider my institution's culture to be friendly. Three, my institution has the reputation of being a great place to work, and four, the reputation of my institution stifles recruitment efforts of quality administrators and faculty. The organizational mission factor consists of items one, the mission statement for my institution is well defined and articulated. Two, it is my perception that the mission statement for my institution is understood and embraced by faculty members. Three, I believe that administrators refer to my institution's mission statement for decision making purposes. The last item reads; the mission statement at my institution is not useful for me. The organizational leadership factor includes items one, leaders at my institution do not often include faculty input in decision making situations. Two, the expectations of the leaders at my institution are transparent. Three, 
the leaders at my institution are well defined and approachable, and four, it is my perception that administrators and faculty members at my institution work collaboratively to reach the institutions' goals (see Table 7).

Table 7

K \& C-OCI Factor Items

\section{Item}

\section{Factor 1: Organizational History and Environment}

My work environment has the tendency to be hostile.

I consider my institution's culture to be friendly.

My institution has the reputation of being a great place to work.

The reputation of my institution stifles recruitment efforts of quality administrators and faculty.

\section{Factor 2: Organizational Mission}

The mission statement for my institution is well defined and articulated.

It is my perception that the mission statement for my institution is understood and embraced by faculty members.

I believe that administrators refer to my institution's mission statement for decision making purposes.

The mission statement at my institution is not useful for me.

\section{Factor 3: Organizational Leadership}

Leaders at my institution do not often include faculty input in decision making situations.

The expectations of the leaders at my institution are transparent.

The leaders at my institution are well defined and approachable.

It is my perception that administrators and faculty members at my institution work collaboratively to reach the institutions' goals.

Descriptive statistics were computed to analyze the frequency rates for each factor included in the uncivil workplace behavior and the organizational culture sections of the instrument. Independent samples $t$-tests and Levene's Test for Equality of Variance tests were used in this particular data-set. According to Field (2009), data sets that do not meet the 
normality assumption and homogeneity of variance, non-parametric tests would be considered to be the most appropriate type of analysis.

The results of the factors related to uncivil workplace behavior that were significant include privacy invasion when $p=.013,(p<.05)$ and gossiping when $p=.023,(p<.05)$ respectively. The one factor related to organizational culture that was significant is leadership when $p=.028,(p<.05)$ respectively. The remaining factors of the UWBQ which are nonsignificant include hostility when $p=.065,(p>.05)$ and exclusionary behavior when $p=.161$, ( $p>.05)$ respectively. The remaining factors related to organizational culture are considered nonsignificant and include artifacts/history/environment when $p=.065,(p>.05)$ and mission when $p=.365,(p>.05)$ respectively (see Table 8$)$.

Table 8

The UWBQ and K \& C-OCI Equality of Variance Test

\begin{tabular}{lcc}
\hline & \multicolumn{2}{c}{$\begin{array}{c}\text { Leven's Test for } \\
\text { Equality of Variance }\end{array}$} \\
& $\mathrm{F}$ & Sig. \\
\hline UWBQ & 1.17 & \\
Hostility & $* 6.29$ & .281 \\
Privacy Invasion & 1.98 & .013 \\
Exclusionary Behavior & $* 5.28$ & .161 \\
Gossiping & & .023 \\
& & \\
\hline K \& C-OCI & 3.44 & .065 \\
Artifacts/History/Environment & .727 & .395 \\
Mission & $* 4.93$ & .028 \\
Leadership & & \\
\hline
\end{tabular}

Note: *Statistically Significant, $p<.05$. 


\section{Types of Analysis}

Descriptive analysis was computed to determine whether or not there were differences in perceptions of incivility and organizational culture between administrators and faculty members in this sample. This section of the chapter reports the findings as a result of the research questions:

RQ1. Do administrators and faculty members perceive incivility/conflict differently?

RQ 2. Do administrators and faculty members perceive organizational culture differently?

RQ 3. Are there relationships between incivility/conflict and organizational culture?

To answer research question one, the independent samples $t$-test was chosen because it compares two means (1) administrators and (2) faculty members' perceptions and is used when the means come from different groups or entities (Field, 2009). The independent samples $t$-test was computed to analyze each factor of the UWBQ for (a) hostility, (b) privacy invasion, (c) exclusionary behavior, and (d) gossiping as they relate to uncivil workplace behavior. The independent samples $t$-test was also used to analyze the overall composite of the UWBQ.

To answer research question two, the independent samples $t$-test was computed to analyze each factor of the K \& C-OCI for (a) organizational history and environment, (b) organizational mission, and (c) organizational leadership as they relate to organizational culture in this sample. An overall composite $t$-test was computed for analysis of the mean responses for the $\mathrm{K} \& \mathrm{C}$ OCI.

To answer research question three, data were computed using Pearson's Correlation Coefficient Matrix. This analysis was used to evaluate the relationship between incivility/conflict and organizational culture in this sample of administrators and faculty 
members. The correlation measures the strength of the relationship from the value of -1 , (strongest negative relationship) to +1 , (strongest positive relationship). Data were compiled in a nominal order from the responses regarding incivility/conflict items from one=never, two $=$ rarely, three $=$ occasionally, four $=$ often, and five=very often. The data were also compiled in a nominal order from the responses regarding organizational culture items from one=strongly agree, two=agree, three=disagree, and four=strongly disagree.

\section{Major Findings}

\section{RQ1. Do administrators and faculty members perceive incivility/conflict}

differently? The UWBQ was used to answer research question one. Multiple $t$-tests were computed and analyzed to measure the differences in means between faculty and administrators for (a) hostility, (b) privacy invasion, (c) exclusionary behavior, and (d) gossiping in reference to the higher education environment.

Hostility. As may be noted in Table 9, Hostility assessed the administrator and faculty perceptions about whether or not others were hostile toward one another. Hostility was determined by the following items: someone raised their voice when speaking to another, colleagues used an inappropriate tone while speaking to each other and colleagues spoke in an aggressive tone of voice toward one another, or rolled their eyes at one another. For administrators, the mean was 9.08 while the faculty mean was 8.96. A $t$-test was computed and yielded $t=-.172, d f=182$, and $p=.281(p>.05)$ (see Table 10). The results indicate that administrator and faculty members' perceptions of hostility are not different. 
Table 9

Hostility Mean Scores of Faculty and Administrators

\begin{tabular}{lcccc}
\hline \multicolumn{1}{c}{ Group } & $\mathrm{N}$ & $\mathrm{M}$ & $\mathrm{SD}$ & $\begin{array}{c}\text { Std. Error } \\
\text { Mean }\end{array}$ \\
\hline Faculty & 153 & 8.96 & 4.03 & .326 \\
Administrators & 34 & 9.08 & 3.31 & .568 \\
& & & & \\
\hline
\end{tabular}

Table 10

Hostility $t$-test for Equality of Means as Rated by Faculty and Administrators

\begin{tabular}{lcccc}
\hline \multicolumn{1}{c}{ Group } & $t$ & $d f$ & $p$ & $\begin{array}{c}\text { Mean } \\
\text { Difference }\end{array}$ \\
\hline $\begin{array}{l}\text { Faculty } \\
\text { vs. }\end{array}$ & -.172 & 182 & $p=.281$ & -.127 \\
Administrators & & & & \\
\hline
\end{tabular}

Privacy invasion. As may be noted in Table 11, the responses to Factor 2, Privacy invasion assessed the administrator and faculty perceptions about whether or not they encountered privacy invasion in their work environment. Privacy invasion was determined by the following items: taking office materials from a desk without returning them or taking items from someone's desk without permission. Privacy invasion was also determined if someone was interrupted while speaking on the phone, when a colleague read communications addressed to another, such as e-mails, and if a colleague opened another's desk drawers without permission. The administrator mean was 8.11 and the faculty mean was 6.87. A $t$-test was computed and yielded $t=-2.55, d f=186$, and $p=.013(p<.05)$ (see Table 12). The results suggest that administrator perceptions regarding privacy invasion are statistically different than that of faculty. 
Table 11

Privacy Invasion Mean Scores of Faculty and Administrators

\begin{tabular}{lcccc}
\hline \multicolumn{1}{c}{ Group } & $\mathrm{N}$ & $\mathrm{M}$ & SD & $\begin{array}{c}\text { Std. Error } \\
\text { Mean }\end{array}$ \\
\hline Faculty & 153 & 6.87 & 2.40 & .194 \\
Administrators & 35 & 8.11 & 3.29 & .557 \\
& & & & \\
\hline
\end{tabular}

Table 12

Privacy Invasion t-test for Equality of Means as Rated by Faculty vs. Administrators

\begin{tabular}{lcccc}
\hline \multicolumn{1}{c}{ Group } & $t$ & $d f$ & $p$ & $\begin{array}{c}\text { Mean } \\
\text { Difference }\end{array}$ \\
\hline Faculty & -2.55 & 186 & $p=.013$ & -1.23 \\
vs. & & & & \\
Administrators & & & & \\
\hline
\end{tabular}

Exclusionary behavior. As may be noted in Table 13, the responses to Factor 3,

Exclusionary behavior assessed the administrator and faculty perceptions about whether or not others excluded them in their work environment. Exclusionary behavior was determined by the following items: a colleague did not consult with them in reference to a decision they should have been involved in, giving unreasonably short notice when cancelling or scheduling events they were required to be at, or failing to inform them of a meeting they should have been informed about. Exclusionary behavior was also determined if a colleague avoided consulting someone when they would normally be expected to do so, was excessively slow in returning phone or e-mail message, failed to pass on information they should have been aware of, or was unreasonably slow seeing to matters they were reliant upon them for. The mean for administrators was 18.54 while the mean for faculty was $16.67 \mathrm{~A} t$-test was computed and 
yielded $t=-1.58, d f=185$, and $p=.161(p>.05)$ (see Table 14). The results indicate that administrator and faculty members' perceptions of exclusionary behavior do not differ.

Table 13

Exclusionary Behavior Mean Scores of Faculty and Administrators

\begin{tabular}{lcccc}
\hline \multicolumn{1}{c}{ Group } & $\mathrm{N}$ & $\mathrm{M}$ & $\mathrm{SD}$ & $\begin{array}{c}\text { Std. Error } \\
\text { Mean }\end{array}$ \\
\hline Faculty & 152 & 16.67 & 6.45 & .523 \\
Administrators & 35 & 18.54 & 5.62 & .951 \\
\hline
\end{tabular}

Table 14

Exclusionary Behavior $t$-test for Equality of Means as Rated by Faculty vs. Administrators

\begin{tabular}{lcccc}
\hline \multicolumn{1}{c}{ Group } & $t$ & $d f$ & $p$ & $\begin{array}{c}\text { Mean } \\
\text { Difference }\end{array}$ \\
\hline $\begin{array}{l}\text { Faculty } \\
\text { vs. }\end{array}$ & -1.58 & 185 & $p=.161$ & -1.87 \\
Administrators & & & & \\
\hline
\end{tabular}

Gossiping. As may be noted in Table 15, the responses to Factor 4, Gossiping assessed the administrator and faculty perceptions about whether or not others gossiped. This factor was measured by the following items: publicly discussing personal information, making snide remarks, and talked and gossiped behind the backs of others. For administrators, the mean was 8.82 while the mean for faculty was 9.17. A $t$-test was computed and yielded $t=.422, d f=182$, and $p=.023(p<.05)$ (see Table 16). Therefore, the administrator perceptions indicated that gossiping was less of a problem than that of the faculty perceptions of the same factor. The results indicate that there is a statistically significant difference in the perception of gossiping between administrators and faculty members. 
Table 15

Gossiping Mean Scores of Faculty and Administrators

\begin{tabular}{lcccc}
\hline \multicolumn{1}{c}{ Group } & $\mathrm{N}$ & $\mathrm{M}$ & $\mathrm{SD}$ & $\begin{array}{c}\text { Std. Error } \\
\text { Mean }\end{array}$ \\
\hline Faculty & 150 & 9.17 & 4.58 & .374 \\
Administrators & 34 & 8.82 & 3.18 & .546 \\
& & & & \\
\hline
\end{tabular}

Table 16

Gossiping t-test for Equality of Means as Rated by Faculty vs. Administrators

\begin{tabular}{lcccc}
\multicolumn{1}{c}{ Group } & $t$ & $d f$ & $p$ & $\begin{array}{c}\text { Mean } \\
\text { Difference }\end{array}$ \\
\hline $\begin{array}{l}\text { Faculty } \\
\text { vs. }\end{array}$ & .422 & 182 & $p=.023$ & .349 \\
Administrators & & & & \\
\hline
\end{tabular}

Overall composite scores. As may be noted in Table 17, responses for administrators and faculty in an overall composite assessed whether or not administrators and faculty experience uncivil workplace behavior. There was an overall possible composite score range of 20 (least hostile) to 100 (very hostile). Faculty, n=149, results show a mean score of 41.7 while administrators, $\mathrm{N}=33$, show an overall mean score of 43.9. A $t$-test was computed and yielded $t$ $=-.756, d f=180$, and $p=.291(p<.05)$ (see Table 18). The overall composite results indicate that faculty members and administrators do not perceive incivility/conflict differently or as a problem at their institution. 
Table 17

Composite Mean Scores for Uncivil Workplace Behavior as Rated by Faculty vs. Administrators

\begin{tabular}{lcccc}
\hline \multicolumn{1}{c}{ Group } & $\mathrm{N}$ & $\mathrm{M}$ & $\mathrm{SD}$ & $\begin{array}{c}\text { Std. Error } \\
\text { Mean }\end{array}$ \\
\hline Faculty & 149 & 41.7 & 15.32 & 1.25 \\
Administrators & 33 & 43.9 & 12.30 & 2.14 \\
& & & & \\
\hline
\end{tabular}

Table 18

Composite $t$-test for Equality of Means as Rated by Faculty vs. Administrators

\begin{tabular}{lcccc}
\hline \multicolumn{1}{c}{ Group } & $t$ & $d f$ & $p$ & $\begin{array}{c}\text { Mean } \\
\text { Difference }\end{array}$ \\
\hline $\begin{array}{l}\text { Faculty } \\
\text { vs. }\end{array}$ & -.756 & 180 & $p=.291$ & -2.15 \\
Administrators & & & & \\
\hline
\end{tabular}

RQ2: Do faculty and administrators perceive organizational culture differently? To answer

this research question, independent samples $t$-tests were computed for (a) organizational history and environment, (b) organizational mission, and (c) organizational leadership. An overall composite mean score for the K \& C-OCI was also computed using the independent samples $t$-test. The following results provide information regarding perceptions of organizational culture between administrators and faculty members in this sample.

Organizational history and environment. As may be noted in Table 19, the responses to Factor 1, Organizational history and environment assessed the administrator and faculty perceptions about whether or not their organizations' environment had the tendency to be hostile, the culture within their environment was friendly, their institution has a good reputation as a great place to work, and if the reputation of the organization stifles recruiting efforts. For administrators, the mean was 7.45 while the faculty mean was 8.48 . A $t$-test was computed and 
yielded $t=2.22, d f=178$, and $p=.065(p<.05)$ (see Table 20). The results indicate that perceptions of organizational history and environment do not differ between administrators and faculty members.

Table 19

Organizational History and Environment Mean Scores of Faculty and Administrators

\begin{tabular}{lcccc}
\hline \multicolumn{1}{c}{ Group } & $\mathrm{N}$ & $\mathrm{M}$ & $\mathrm{SD}$ & $\begin{array}{c}\text { Std. Error } \\
\text { Mean }\end{array}$ \\
\hline Faculty & 147 & 8.48 & 2.52 & .208 \\
Administrators & 33 & 7.45 & 1.87 & .325 \\
\end{tabular}

Table 20

Organizational History and Environment $t$-test for Equality of Means as Rated by Faculty vs. Administrators

\begin{tabular}{lcccc}
\hline \multicolumn{1}{c}{ Group } & $t$ & $d f$ & $p$ & $\begin{array}{c}\text { Mean } \\
\text { Difference }\end{array}$ \\
\hline $\begin{array}{l}\text { Faculty } \\
\text { vs. }\end{array}$ & 2.22 & 178 & $p=.065$ & 1.03 \\
Administrators & & & & \\
\hline
\end{tabular}

Organizational mission. As may be noted in Table 21, the responses to Factor 2, Organizational mission assessed the administrator and faculty perceptions about whether or not the mission statement at their institution was well defined and articulated, is understood and embraced by faculty members, that administrators refer to the mission statement for decision making purposes, and if the mission statement was useful. The mean for faculty was 8.78 and 8.20 for administrators. A $t$-test was computed and yielded $t=1.25, d f=183$, and $p=.395$ $(p>.05)$ (see Table 22). The results indicate that both administrators and faculty members perception of their organizational mission is not an important element within their institution. 
Moreover, administrators and faculty members do not perceive the purpose of the mission differently.

Table 21

Organizational Mission Mean Scores of Faculty and Administrators

\begin{tabular}{lcccc}
\hline \multicolumn{1}{c}{ Group } & $\mathrm{N}$ & $\mathrm{M}$ & $\mathrm{SD}$ & $\begin{array}{c}\text { Std. Error } \\
\text { Mean }\end{array}$ \\
\hline Faculty & 151 & 8.78 & 2.41 & .196 \\
Administrators & 34 & 8.20 & 2.45 & .421 \\
& & & & \\
\hline
\end{tabular}

Table 22

Organizational Mission $t$-test for Equality of Means as Rated by Faculty vs. Administrators

\begin{tabular}{lcccc}
\hline \multicolumn{1}{c}{ Group } & $t$ & $d f$ & $p$ & $\begin{array}{c}\text { Mean } \\
\text { Difference }\end{array}$ \\
\hline $\begin{array}{l}\text { Faculty } \\
\text { vs. }\end{array}$ & 1.25 & 183 & $p=.395$ & .575 \\
Administrators & & & & \\
\hline
\end{tabular}

Organizational leadership. As may be noted in Table 23, the responses for Factor 3, Organizational leadership assessed the administrator and faculty perceptions about whether or not the leadership at their institution was good or poor. The results were based upon whether administrators and faculty perceived that the leaders at their institution do not often include faculty input in decision making situations, the expectations of the leaders are transparent, the leaders are well defined and approachable, and that administrators and faculty work collaboratively to reach the institution's goals. A $t$-test was computed and yielded $t=2.79, d f=$ 181 , and $p=.028(p<.05)$ (see Table 24). The results indicate that administrators and faculty members perceive organizational leadership differently. 
Table 23

Organizational Leadership Mean Scores of Faculty and Administrators

\begin{tabular}{lcccc}
\hline \multicolumn{1}{c}{ Group } & $\mathrm{N}$ & $\mathrm{M}$ & $\mathrm{SD}$ & $\begin{array}{c}\text { Std. Error } \\
\text { Mean }\end{array}$ \\
\hline Faculty & 149 & 9.96 & 2.82 & .231 \\
Administrators & 34 & 8.52 & 2.09 & .358 \\
& & & & \\
\hline
\end{tabular}

Table 24

Organizational Leadership $t$-test for Equality of Means as Rated by Faculty vs. Administrators

\begin{tabular}{lcccc}
\hline \multicolumn{1}{c}{ Group } & $t$ & $d f$ & $p$ & $\begin{array}{c}\text { Mean } \\
\text { Difference }\end{array}$ \\
\hline $\begin{array}{l}\text { Faculty } \\
\text { vs. }\end{array}$ & 2.79 & 181 & $p=.028$ & 1.43 \\
Administrators & & & & \\
\hline
\end{tabular}

Overall composite scores. As may be noted in Table 25, the independent samples $t$-test was computed to assess administrator and faculty perceptions of overall organizational culture. With an overall possible composite score range of 12 (good organizational culture) to 48 (negative organizational culture), on average, faculty and administrators indicated that the culture at their institution is positive. For administrators, the mean was 24.06 while the faculty mean was 27.21. A $t$-test was computed and yielded $t=2.52, d f=177$, and $p=.114(p>.05)$ (see Table 26). The overall results indicate that, on average, faculty members and administrators do not perceive organizational culture to be positive. The results indicate that administrators and faculty members do not perceive organizational culture differently. 
Table 25

Composite Mean Scores of Organizational Culture by Faculty and Administrators

\begin{tabular}{lcccc}
\hline \multicolumn{1}{c}{ Group } & $\mathrm{N}$ & $\mathrm{M}$ & $\mathrm{SD}$ & $\begin{array}{c}\text { Std. Error } \\
\text { Mean }\end{array}$ \\
\hline Faculty & 146 & 27.21 & 6.68 & .553 \\
Administrators & 33 & 24.06 & 5.43 & .945 \\
& & & & \\
\hline
\end{tabular}

Table 26

Composite t-test for Equality of Means as Rated by Faculty vs. Administrators

\begin{tabular}{lcccc}
\hline \multicolumn{1}{c}{ Group } & $t$ & $d f$ & $p$ & $\begin{array}{c}\text { Mean } \\
\text { Difference }\end{array}$ \\
\hline $\begin{array}{l}\text { Faculty } \\
\text { vs. }\end{array}$ & 2.52 & 177 & $p=.114$ & 3.15 \\
Administrators & & & & \\
\hline
\end{tabular}

\section{RQ3: Are there relationships between the institution's perceived culture and}

incivility/conflict? To answer research question three, the Pearson's $r$ correlation coefficient was computed to evaluate the relationship between perceptions of incivility/conflict and organizational culture. When interpreting the relationships between the two variables, the following guidelines were used to measure the strength or weakness of the correlations. A weak relationship is represented when $r=+.1$ to +.3 . A moderate or medium relationship between the variables is represented when $r=+.31$ to +.5 while a strong relationship between the variables is typically represented when $r=+.51$ to +1.0 .

As represented in Table 27, there is a strong relationship between administrators and faculty members' perceptions of uncivil workplace behaviors and organizational culture.

The administrator perceptions indicate a strong correlation and relationship when $r=$ $.584, \mathrm{n}=32, p=.000$. Similarly, faculty members' indicate a strong relationship between uncivil 
workplace behavior and organizational culture when $r=.502, \mathrm{n}=149, p=.000$. The notion of how civil the workplace is perceived by administrators and faculty members in this sample is strongly related to organizational culture. A scatterplot was also computed and summarizes the overall relationship between incivility/conflict and organizational culture. Therefore, faculty and administrators indicate their work environments to be non-hostile with good organizational culture (see Figure 4).

Table 27

Administrator and Faculty Member Pearson's $r$ Correlations between UWBQ and K \& C-OCI

\begin{tabular}{l|c}
\hline \multicolumn{1}{c|}{ Groups } & UWBQ/K \& C-OCI \\
\hline Administrators & $r=.584$ \\
& $p=.000$ \\
\hline Faculty Members & $r=.502$ \\
& $p=.000$ \\
\hline
\end{tabular}

*Correlation is significant at the 0.01 level (2-tailed).

There is a moderate to strong positive correlation between hostility and organizational environment $r=.538, \mathrm{n}=183, p=.000$. The correlation between privacy invasion and organizational environment is moderate $r=.321, \mathrm{n}=183, p=.000$. There is also a positive strong relationship between exclusionary behavior and organizational environment $r=.519, \mathrm{n}=$ $183, p=.000$ and between gossiping and organizational environment $r=.564, \mathrm{n}=183, p=.000$. Overall, there is a moderate to strong positive relationship between incivility/conflict and the organizational environment (see Table 28).

After analyzing the relationship between hostility and organizational mission, the results indicate a weak yet positive correlation $r=.186, \mathrm{n}=189, p=.010$. Further results indicate a similar correlation between privacy invasion and organizational mission $r=.174, \mathrm{n}=189, p=$ .017. There is a weak but positive correlation between exclusionary behavior and organizational 
mission $r=.205, \mathrm{n}=189, p=.005$ with a similar somewhat weak but positive relationship between gossiping and organizational mission $r=.251, \mathrm{n}=189, p=.001$. The overall correlation between incivility/conflict and organizational mission is a positive weak relationship (see Table 28).

Analysis of the correlation between hostility and organizational leadership $r=.387$, $\mathrm{n}=186, p=.000$ is positive yet moderate while the relationship between privacy invasion and organizational leadership is very weak yet positive $r=.162, \mathrm{n}=186, p=.027$. There is a moderately strong correlation between exclusionary behavior and organizational leadership $r=$ $.444, \mathrm{n}=186, p=.000$ with a similar correlation between gossiping and organizational leadership $r=.455, \mathrm{n}=183, p=.000$. The overall results indicate a moderate yet positive correlation between incivility/conflict and organizational leadership. The results of the Pearson $r$ correlation coefficient computed to analyze the relationship between incivility/conflict and organizational culture $r=.489, \mathrm{n}=179, p=.000$ indicate positive moderate to strong relationship (see Table 29). 
Table 28

Pearson's $r$ Correlation Coefficient Matrix

$$
\text { Uncivil Workplace Behavior }
$$

\begin{tabular}{|c|c|c|c|c|c|}
\hline \multirow{7}{*}{ 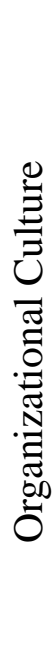 } & & Hostility & $\begin{array}{l}\text { Privacy } \\
\text { Invasion }\end{array}$ & $\begin{array}{l}\text { Exclusionary } \\
\text { Behavior }\end{array}$ & Gossiping \\
\hline & History and & $r=.538$ & $r=.321$ & $r=.519$ & $r=.564$ \\
\hline & & $p=.000$ & $p=.000$ & $p=.000$ & $p=.000$ \\
\hline & Mission & $r=.186$ & $r=.174$ & $r=.205$ & $r=.251$ \\
\hline & & $* p=.010$ & $* p=.017$ & $* p=.005$ & $* p=.001$ \\
\hline & Leadership & $r=.387$ & $r=.162$ & $r=.440$ & $r=.455$ \\
\hline & & $p=.000$ & $* p=.027$ & $p=.000$ & $p=.000$ \\
\hline
\end{tabular}

Note: **Correlation is significant at the 0.01 level (2-tailed)

*Correlation is significant at the 0.05 level (2-tailed)

Table 29

Pearson's $r$ Correlation Coefficient overall relationship between incivility/conflict and organizational culture

$$
\text { Uncivil Workplace Behavior }
$$

\begin{tabular}{ll}
\hline Organizational Culture & $r=.489$ \\
& $\mathrm{~N}=179$ \\
& $p=.000$
\end{tabular}

Note: *Correlation is significant at the 0.01 level (2-tailed). 
Figure 4

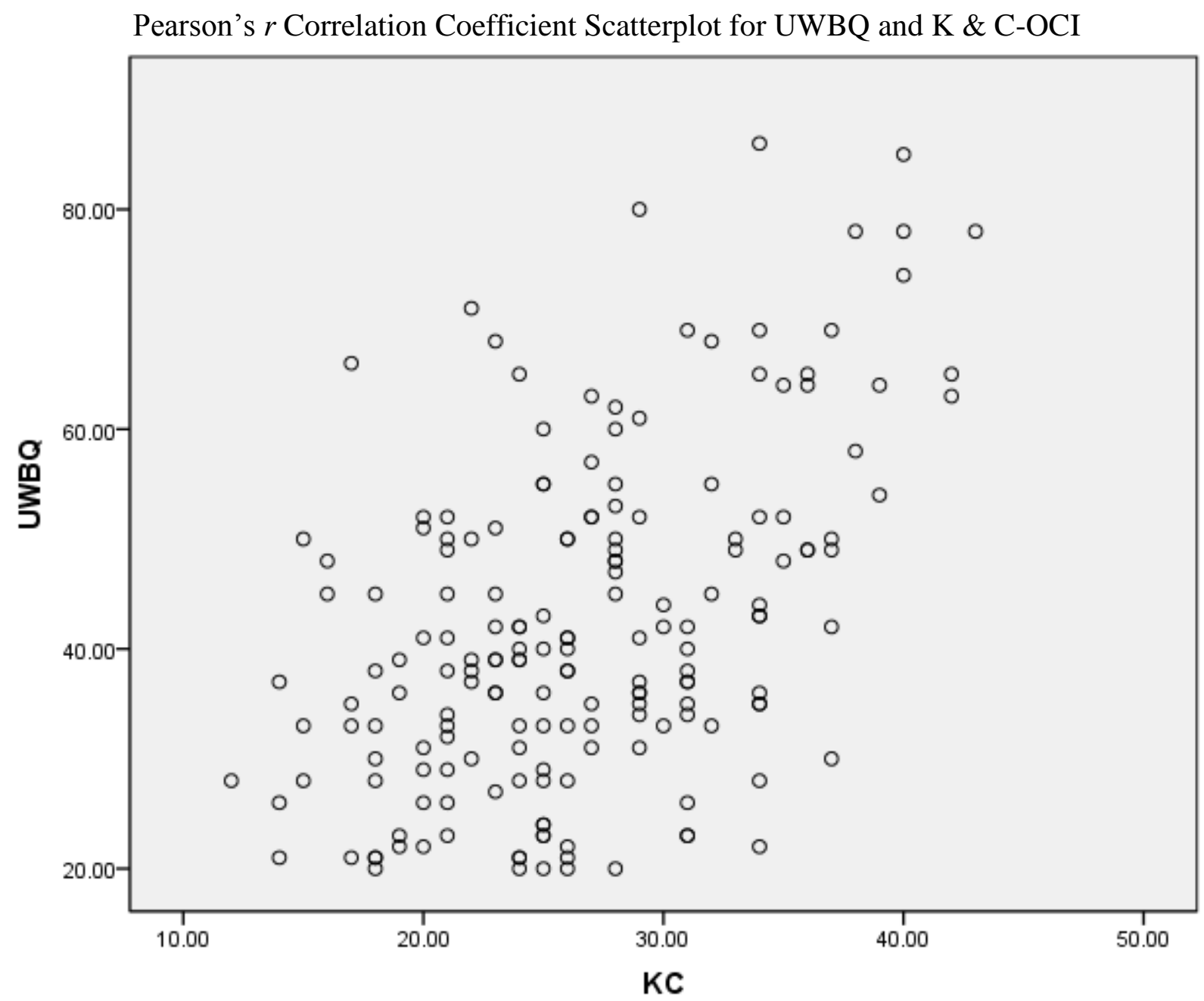




\section{Summary of the Data Analysis}

The results of the data were collected from a survey that was developed to gain an understanding of the perceptions of incivility/conflict and organizational culture according to administrators and faculty members were presented in this chapter. The data collected are indicators of administrator and faculty members' perceptions of (a) hostility, (b) privacy invasion, (c) exclusionary behavior, and (d) gossiping in the higher education environment. The results of this focal point of uncivil workplace behavior were used to identify perceptions of incivility/conflict and answered research question one: Do administrators and faculty members perceive incivility/conflict differently?

With an overall possible composite score range of 20 (least hostile) to 100 (very hostile), faculty and administrators did not indicate that there was any significant findings that their work environments in higher education are hostile. Faculty, n=149, results show a mean score of 41.7 while administrators, $n=33$, show an overall mean score of 43.9. Therefore, administrators and faculty members of this sample do not perceive incivility/conflict differently.

The results of the data collected regarding administrator and faculty members' perceptions of organizational culture in this data set were presented. The data collected identified perceptions of (a) organizational history and environment, (b) organizational mission, and (c) organizational leadership. The results of this element of the study were used to answer research question two: Do administrators and faculty members perceive organizational culture differently?

There was an overall possible composite score range of 12 (good organizational culture) to 48 (negative organizational culture). Faculty, $n=146$, results show a mean score of 27.21 while administrators, $n=33$, show an overall mean score of 24.06 . The results indicate that 
administrators perceive their organizational culture to be slightly better than that of the faculty members. The overall results indicate that faculty members and administrators do not perceive organizational culture differently.

The Pearson's $r$ Correlation Coefficient Matrix was used to answer research question three: Are there relationships between incivility/conflict and organizational culture? The results of the Pearson $r$ correlation coefficient analyzed the relationship between incivility/conflict and organizational culture $r=.489, \mathrm{n}=179, p=.000$. The results indicate a positive moderate to strong relationship. Therefore, faculty and administrators in this data set indicate the culture to be good and their work environment not hostile.

The following chapter will focus more specifically on the results of the survey with a detailed discussion regarding the relevance of the study to higher education. The next chapter will also provide interpretation of the findings, applicable relationships of this study to previous studies and research, recommendations for practice for administrators and faculty in higher education regarding incivility/conflict and culture, and recommendations for future research. 


\section{Summary and Discussion}

\section{Summary of the Study}

This study was conducted to explore administrator and faculty perceptions of incivility, organizational culture, and their corresponding relationships. Uncivil behaviors within small and large groups of individuals can be perceived as unproductive when trying to meet organizational goals and objectives. Prolonged and repeated participation in uncivil acts by administrators and faculty members in higher education organizations creates not only a culture of conflict but also institutional dysfunction. These uncivil acts share certain sets of behavioral commonalities which overlap and often create particular patterns of behavior which have clear hostile intent that may occur over an extended period of time (Penney \& Spector, 2005).

Due to the cultural diversity associated with institutional development, as it pertains to administrators and faculty within institutions of higher education, it is important to investigate how institutional culture contributes to higher levels of conflict, which prevent or inhibit personal satisfaction or organizational agendas. Consequently, it is the responsibility of organizational leadership to establish and nurture a culture of trust and stability. Leaders who understand the dynamics of uncivil behaviors within their institutional culture hopefully have skills and knowledge that allow them to counter the dysfunctional culture (Kefela, 2010).

One early organizational culture predecessor, Edgar Schein conducted many studies opening the contextual background for informed studies of organizational behavior. Schein investigations assert that an organization's culture develops in concert with environmental coping mechanisms (Schein, 2010). Schein contends that many of the problems organizational leaders are confronted with are the result of their inability to objectively evaluate the organization's culture. 
According to the literature, workplace incivility is on the rise and increasing (Pearson \& Porath, 2005). Hence, the effects of uncivil behaviors in organizations and institutions of higher education likely propose severe consequences. Incivility gives rise to conflict, and conflicts demand responses from leaders eliminating negative effects.

The problem is that although this phenomenon of incivility has been studied, it is not well understood in terms of how administrators and faculty members in higher education perceive uncivil behavior. It was therefore important to examine administrator and faculty members' perceptions of organizational culture, in terms of, how it is that uncivil behaviors and culture are related and/or whether those relationships were understood as positive or perceived as negative.

Two instruments were used in conducting this study within this sample of higher education. The UWBQ developed by Martin and Hine (2005) was used to evaluate administrator and faculty member perceptions for uncivil behaviors including hostility, privacy invasion, exclusionary behavior, and gossiping. The K \& C-OCI developed by Kendig and Chapman (2012) was used to evaluate organizational culture, which included evaluating organizational environment, organizational mission, and organizational leadership.

The participants in this study included administrators, executive decision making staff, tenured and non-tenured faculty members with part time or adjunct faculty members from an institutional sampling that included three institutions of higher education with closely aligned classifications based on the Carnegie Classification system (Carnegie Classifications (2010).

\section{Discussion of the Findings}

The significant aims of this study were to identify and examine administrator and faculty members' perceptions of uncivil workplace behavior and organizational culture. Further, the study was aimed at determining the relationship between uncivil workplace behaviors and 
organizational culture. To date, there has been a minimal amount of research conducted that specifically targeted administrators and faculty members in the contexts of higher education environments. Hence, three specific research questions were developed for this study:

RQ 1. Do administrators and faculty members perceive incivility/conflict differently?

RQ 2. Do administrators and faculty members perceive organizational culture differently?

RQ 3. Are there relationships between the institution's perceived culture and incivility/conflict?

RQ 1: Do administrators and faculty members perceive incivility/conflict differently? There were four individual factors used in the study specifically relative to uncivil workplace behaviors (a) hostility, (b) privacy invasion, (c) exclusionary behavior, and (d) gossiping, all of which are discussed individually in the following detailed sections.

Hostility. According to Vega \& Comer (2005), uncivil behaviors might include rude, foul, and abusive language. Similarly, Penney \& Spector (2005) refer to these actions as counterproductive workplace behaviors and include verbal abuse as an indicator of uncivil behavior. Studies conducted by Andersson \& Pearson (1999) also indicate that such uncivil behaviors can lead to further conflict or more aggressive acts resulting in an upward spiral of perceived uncivil behaviors. These behaviors may result in anger or even revenge toward colleagues. Romano (1994) conducted a study in organizations and found that over 20 percent of human resource managers experienced violence and aggression in the workplace within the past 20 years. There were an additional 33 percent of those managers who actually reported threats of violent acts within their organization. 
Contrary to the results of the previous studies, the results from this particular sample indicate that administrators and faculty members do not perceive their work environments to be hostile. The perceptions of hostility; as defined in the UWBQ, between administrators with a mean score of 9.08 and faculty members with a mean of 8.96 in this particular study are insignificant. Is it possible that administrators and faculty members have taken an egalitarian approach to their work environments? With the notion of all being equal through their eyes and if hostile behaviors are occurring, then one might conclude that this type of behavior it is not being shared with colleagues for fear of social labeling. Moreover, if this type of behavior occurs, then possibly those involved are immune to the behavior and therefore; do not see it as a threat to the work environment. If there are hostile behaviors being practiced within these work environments, might there be reasons that the people who have experienced or observed hostile behaviors are covering for another?

A replica of this study could be considered for future research isolating the hostility factor and using it as the only variable. Another suggestion for further research would be to use hostility and examine the level at which it alone contributes to uncivil workplace behaviors and organizational function. Further research using a larger sample size of administrators and faculty members in a replica of this study might result in further clarification of the incidence in which hostility occurs within institutions of higher education.

Privacy invasion. For this particular study, privacy invasion was determined by such behaviors as colleagues listening to private phone conversations, taking or using materials from a colleagues office without permission, and more frequently, colleagues gaining access to another's e-mail and using that information inappropriately. With these aspects of privacy invasion in mind, the administrators with a mean score of 8.11 in this sample indicated that 
privacy invasion was somewhat of an issue whereas the faculty members with a mean score of 6.87 did not indicate privacy invasion was an issue. The end result of this finding was insignificant. However, using a larger sample size with privacy invasion as a single variable would increase the ability to generalize the occurrence of this type of behavior.

Consistent with the hostility factor, privacy invasion could also be isolated in a future replica of this study examining frequency levels in which this behavior occurs at different professional levels in higher education. For example, does privacy invasion occur more frequently among department chairs, deans, vice presidents, or even top level leaders in the overall organizational structure? Additionally, future research would be beneficial in examining a larger sample of administrators and faculty members and what prompts or precipitates this type of behavior in the higher education environment.

Exclusionary behavior. Consequently, the administrators and faculty members' in this sample do not have significantly different perceptions regarding exclusionary behavior. The responses were based upon issues that commonly occur in the workplace such as colleagues not including someone in a meeting that they would normally be included in, failing to pass on important information to a colleague that might be needed in a decision making process, and colleagues intentionally avoiding or not consulting one another when they would normally do so. According to Wall and Callister (1995) perceptions of exclusionary behavior might be linked to interpersonal factors such as perceptual interface (other's intentions, distrust, and misunderstanding), behavior (reduction of one's outcomes, blocking goals, and power struggles), and structure (closeness, status differences, preferential treatment, and symbols). Contrary to the notion of these researchers, this group does not perceive exclusionary behavior to be an issue in their work environments. 
According to the administrators in this sample with a mean score of 18.54 , they indicate that they experience exclusionary behavior more frequently than that of faculty members with a mean score of 16.67. Looking at the results of this study, one might be curious to further explore more fully to determine on which administrative level this type of behavior most frequently occur. Therefore, a suggestion for a future study might warrant exploring exclusionary behavior only at the administrative and decision making levels within institutions of higher education. The use of a mixed methods study regarding exclusionary behavior at only large research specific institutions might expand the data collection on this topic while providing enlightening results for leaders.

With the faculty member sample in mind, further research is suggested in examining perceptions of exclusionary behavior among different professional levels of faculty including adjunct and part time faculty to (a) determine levels of various exclusionary behaviors they experience; (b) to ascertain how these behaviors impact their decision to teach in higher education; and, (c) to further explore environmental characteristics which contribute to prolonged teaching, or extended employment contracts for part-time or adjunct faculty members.

Gossiping. The simple nature of gossiping, in and of itself; damages both individuals and organizations. According to Layne (2013), gossiping has the potential to (a) decrease staff morale, (b) create mistrust among colleagues, and (c) promote a negative work environment. Gossiping can also have adverse effects on workplace reputations and may even encourage good employees to leave the organization. The University of Virginia Health System suggests that those who engage in gossiping think that it may increase their chances of fitting in to the work environment while giving them a sense of being important (Layne, 2013). For the purposes of this study, the participants based their responses on statements such as: (a) colleagues publicly 
discussed personal information with others, (b) making snide remarks about another colleague, and (c) talked behind the backs of others. With these concepts in mind, are people gossiping or just engaging in water cooler talk or idle chit-chat? According to Abbajay (2008) idle chit-chat can be viewed as value neutral, whereas gossip is most often negative in nature, embarrassing, and intentionally inflammatory toward target-specific persons. The idea of gossiping seems harmless yet can be personally dangerous and destructive in the workplace. Moreover, gossiping has the potential to decrease morale, strain working relationships, and result in creating an unproductive work environment such that colleagues second-guess one another and ultimately refuse to work together. The term gossiping may also be viewed as workplace deviance with behavior that may violate organizational norms and values while threatening the overall wellbeing of the organization (Robinson \& Bennett, 1995).

The results of this study indicate that faculty members with a mean score of 9.17 say yes, gossiping takes place at my institution and expands beyond idle chit-chat whereas administrators with a mean score of 8.82 indicate that they do not engage in gossiping nor do they think it is a problem at their institution. The possibility exists that administrators in this sample do not see gossiping as an issue simply because the nature of their work prevents them from engaging in such behavior. Since there is no evidence for how, and where gossiping takes place within this sample, it would be interesting to further investigate gossiping through another qualitative approach. This approach would allow a researcher to actually hear conversations, as well as, the most common areas in which gossiping takes place among colleagues at either the administrative or faculty member levels. Further ideas for research would be to departmentalize gossiping in higher education. For example, examine the comparative frequency levels of gossiping among Biology department faculty members as opposed to faculty members in the English department. 


\section{RQ 2: Do administrators and faculty members perceive organizational culture differently?}

The K \& C-OCI instrument was developed specifically for this study to assess the perceptions of administrators and faculty members based upon three factors: (a) organizational history and environment, (b) organizational mission, and (c) organizational leadership. These factors are discussed individually in the following sections.

Organizational history and environment. According to the literature, Seymour (2003) supports the idea of acknowledging the history of the organization, building awareness, learning empathy, and being able to recognize fears as powerful tools are important in building and sustaining peace within the organization and among groups. Moreover, Mayer (2000) contends that recognizing the basic needs of human beings means understanding the organization's environment in terms of communications, history, emotions, structure, and values. Consistent with Mayer (2000) and Pierre and Peppers (1976) suggest that one cause for the rise in uncivil behavior in the workplace is due to societal components such as values and beliefs which create incidences about that which is ethically right and, conversely, ethically wrong. Hence, who is it that makes such determinations for that which is ethically right and wrong within the organizational culture? Do the administrators encourage good working environments by inviting colleagues and faculty members to engage in cooperative decision making processes? Do the faculty members assert themselves, learning about their institution's history while preserving organizational values? Do administrators and faculty members embrace the history of their institution and use that as a guide in their professional efforts?

Interestingly, the results of this factor are consistent with that of the hostility factor where faculty members with a mean score of 8.48 and administrators with a mean score of 7.45 do not perceive organizational history and environment differently. Administrators and faculty 
members in this sample indicate that their organizations are not hostile work environments; they are culturally friendly; and, the institution is perceived as being a cordial work environment.

Organizational mission. According to the literature, Goffman (1959) contends that culture should be friendly, cooperative, and presentable in appearance. However, the part of organizational culture that is not noticed can be ambiguous and hidden from the view of others on purpose in an attempt to cover up dysfunction of an organization. With regard to higher education, this concept describes the culture of academe whereas institutional missions and philosophies help shape the academic culture (Goffman, 1959). Schein (2010) believes that organizational culture is typically seen as an abstraction by which the forces created within the social and organizational structures can be powerful because they occur outside of one's awareness. Organizational culture is defined not only by the history and environment of the institution, but also by the values and beliefs of the people within the organization. It is equally important for the people within the organization to understand the mission of the institution, hence aligning academic practices with the overall concept of the mission. Culture becomes a key component of the institution leaders' efforts to achieve the institution's goals and mission, while improving organizational effectiveness (Kefela, 2010).

With such concepts in mind, factor two of the K \& C-OCI was developed in an effort to gain an understanding for how administrators and faculty members perceived their specific organization's mission. The items posed included: (a) if the mission was well defined and articulated; (b) if the mission is embraced by faculty members; and, (c) if the mission statement was then found useful in daily institutional practices. The results indicate that administrators with a mean score of 8.20 and faculty members with a mean score of 8.78 have almost identical perceptions for the usefulness of their institution's mission statement. From a leadership 
standpoint, one might think that the administrators score would be much less than that of the faculty members indicating that they fully understand, embrace, and operate as set forth in the mission statement. Do administrators and faculty members truly understand what a mission statement is and how it impacts the overall functions of the institution?

Future research efforts might entail isolating the organizational mission concept from the $\mathrm{K} \& \mathrm{C}-\mathrm{OCI}$ by using the mission statement and criteria therein, as a combined variable for a study. Further, sampling administrators in a research-specific institution would contribute to existing knowledge of how it is mission statements are used in defining the culture of the institution. A replica of this study could be conducted from an administrators stand point examining how mission statements are initiated, designed, developed, implemented, and then prioritized for research-specific institutions?

Organizational leadership. Pietersen (2005) suggests that due to the increasing presence of certain types of uncivil behaviors in the workplace, there exists the potential for conflict within the organization. Hence, these uncivil behaviors must be a focal point of institutional leaders. Consistent with the works of Andersson \& Pearson (1999) and Pearson, Andersson, \& Porath (2000), uncivil behavior affects interpersonal relations, organizational departure, and organizational functioning which must be acknowledged and effectively resolved by leaders. Collins (2009) supports the notion that uncivil behavior is inevitable in the workplace and although conflict may vary from organization to organization, it is ultimately the responsibility of leaders to identify, minimize, and manage workplace incivilities. It is critical for leaders to have a clear understanding of the process of conflict and incivility in order to maximize productivity while decreasing destruction within the organizational environment (Fisher, 2000). 
The results of this particular factor were based upon responses from administrators and faculty members regarding: (a) if the overall leadership was good or poor; (b) if leaders included faculty members in the decision making processes; and, (c) if administrators and faculty members work cooperatively to meet their institutional goals. Overall, the administrators with a mean of 8.52 indicated that the leadership at their institution was very good. Contrary to the perceptions of the administrators; faculty members with a mean score of 9.96 , indicated that leadership at their institution was not as good and lacked cooperation in daily academic practices. One might conclude from this sample of administrators that they think they are wonderful leaders and their institution operates and functions smoothly under their watch. On the other hand, the results further indicate that the faculty members in this sample, at least, comparatively, disagree with the administrators' perceptions. Further investigation using solely the leadership factor would be interesting at the research-specific, private, foundation supported institutions. Would there be a significant difference in the perceptions of administrators' leadership qualities at a research-specific institution as opposed to a private, fiscally-sound foundation institution? Further quantitative studies can be conducted in an effort to determine how administrators measure their own leadership styles and skills and how these skills are integrated into their leadership roles.

\section{RQ 3: Are there relationships between the institutions' perceived culture and} incivility/conflict? Schein (2010) contends that culture is empirically based and that researchers and organizations use it to define norms and practices which organizations or institutions develop over time in an effort to manage people, their values, and the organization. The very concept of culture dictates the climate of an organization thus confusing the culture with what it is as opposed to what it ought to be in an organization. Managerial literature suggests that 
creating a culture is necessary for organizations to perform effectively. Hence, having a strong positive culture encourages and enhances higher performance levels within the organization or institution (Schein, 2010).

Senge (2006) suggests that individuals possess ideologies that may result in organizational conflict or dissonance due to the ideologies which the individual embraces and those espoused by the organization. Hence, these ideologies may contribute to how administrators and faculty members perceive organizational culture. The results of the particular sample of administrators and faculty members indicate that the relationship between the institutions' perceived culture and incivility is clearly positive. The people in this sample believe that their institution is not a hostile place in which to work and that their institution has a positive culture with which they knowingly and willing conform. The overall results of the UWBQ and the $\mathrm{K} \& \mathrm{C}-\mathrm{OCI}$ indicate that there are categorically good places to work in higher education. It would be interesting to conduct further research using only the K \& C-OCI instrument at a larger institution and with a larger sample population. The results of another study based on culture might further inform leaders of their effectiveness in the overall functioning of their institution. Moreover, further research would add to the breadth of knowledge already existing on culture from researchers such as Schein, Kefela, and Tierney.

\section{Conclusions}

Although the overall results of this study indicate that the administrators and faculty members who participated did not perceive the notion of incivility and organizational culture differently, there are three distinct conclusions drawn from the research. The combination of the UWBQ and the K \& C-OCI provided a different perspective on how incivility and culture are perceived by this particular sample. 
First, understanding the history, traditions, and environment of the institution should be vitally important to leaders as this provides a basis for what guides their work. The idea of leaders not being able to tell the story of the history and environment of their institution may be due to the risk of exposing certain information. Therefore, leaders in this study may have been hesitant to either participate in the study or if they did participate, answer the items contained in the survey honestly. Interestingly, the perceptions of the administrators and faculty members regarding the importance of understanding history, is in the middle of the scale. One might wonder why the leaders perceptions are not significantly different and why they their overall scores did not end up at the much lower end of the scale. Leaders must embrace and value the history of their institution as this helps to define and guide the functions and goals of the institution. Might leaders have an identity gap between the values that they stand for versus the way they are operating?

Second, understanding, embracing, and using the mission to guide institutional operations should be a priority of leaders, hence, they are typically the group who develops the mission accordingly for all to work by. The striking finding from this study suggests that the administrators have almost identical perceptions as that of the faculty for the usefulness of the mission which is, again, in the middle of the scale. Is it somewhat unusual, based upon the results, that the leaders in this sample seemingly do not value the importance of their institutional mission? The results suggest that the leaders as well as the faculty members perceive the mission to be visible, however, not something that they truly need to guide their work efforts.

Third, the participants of this study were among three institutions of higher education with similar Carnegie classifications. All three were public, four-year liberal arts universities with similar student populations. Professional levels of administrators and faculty members 
were also similar. Might the conclusion be drawn from this small sample of administrators and faculty members from institutions of similar classifications; that the results of this study would be similar between all institutions of higher education falling into the same Carnegie classification?

Finally, the leaders in this sample indicate that their leadership abilities are quite good which might suggest that they gauge their own leadership qualities through rose colored glass. Is it true that the administrators truly perceive their institutions to be ultimately non-hostile while functioning under well-defined leadership skills? Consistent with the results of the hostility factor, the administrators and faculty members both do not indicate that their work environments are hostile and that leadership is a positive aspect of their work environment.

In terms of perceptions of uncivil workplace behavior and organizational culture, the findings in this particular study suggest that administrators and faculty members do not perceive their institutions to be hostile, nor do their perceptions of organizational culture significantly differ. Taking into consideration the positive correlational relationship between incivility and organizational culture within this small sample of higher education, it would be premature to make the assumption that incivility occurs and that organizational culture is positive in larger samples of the higher education environment. Therefore, consistent with Cortina et al. (2001), further research is warranted to measure incivility and organizational culture in other higher education environments. Moreover, to further support the findings from Martin \& Hine (2005) a longitudinal study from which different findings and conclusions can be drawn regarding other influences of uncivil behavior would be beneficial for other higher education environments. Additional research seeking information regarding specific conditions that either strengthen or weaken the relationship between incivility and organizational culture would also be beneficial. 


\section{Recommendations for Practice}

1. This study can serve as a contribution to the professional development efforts of administrators and faculty members in higher education. The findings of this study can be used in creating a broader awareness for how incivility and institutional culture are related and how the two concepts impact academic functioning.

2. The findings of this study may be used in creating a more effective teaching and learning environment for administrators and faculty members. Hence, raising awareness for how uncivil behaviors contribute to stifling necessary processes that undermine organizational goals.

3. Administrators must be afforded opportunities to work cooperatively within their institution of higher education in order to develop a more cohesive aspect of the institutions goal seeking and growth efforts.

4. Faculty members must be included in institutional decision making efforts through administrators' efforts to include them in departmental, interdepartmental, and university wide professional development programs.

5. By understanding uncivil behaviors, administrators and faculty members can make individual contributions that decrease harmful effects of incivility.

6. Administrators and faculty members must have a clear understanding for their institution's culture and mission and whether or not there is an overall conformity to that culture. This can be accomplished by providing special seminars and retreats that enhance administrator and faculty members' contributions to creating a positive culture. 
7. Provide training specifically for administrators regarding the history of the institution and the current work environment in an effort to decrease levels of toxicity transferred to others within the institution.

8. Provide seminars for leaders to help them understand how to discern the level of climate health by communicating positive attributes to the faculty.

\section{Recommendations for Future Research}

1. An extension of this study should be conducted using a larger sample of administrators and faculty members in higher education.

2. This study can also be replicated by using (1) only research-specific institutions, (2) incorporate and sample only instructional, liberal arts teaching institutions, (3) sample only private institutions, and, (4) sample only community colleges.

3. Further research can be conducted using each of the contributing factors within uncivil workplace behaviors, as individual indicators: (a) hostility, (b) privacy invasion, (c) exclusionary behavior, and (d) gossiping. This type of research can make an additional contribution to the higher education environment, in so far as, how it is each factored indicator contributes to levels of overall incivility.

4. Organizational culture might further be researched for how it is that culture specifically contributes to the overall functionality in higher education institutions.

5. A demographic extension of this study could also be conducted exploring only specific departments, gender, professional rank, age, and years of service within institutions of higher education. 
6. A qualitative study would be useful in gaining information regarding how uncivil behaviors may change among administrators and faculty members upon completion of professional development workshops specifically designed around incivility.

7. An additional extension of this study might include an institutional ethnography for which a random, interview sampling within multiple organizational structures takes place.

8. Testing the reliability of the $\mathrm{K} \& \mathrm{C}-\mathrm{OCI}$. 


\section{References}

Abbajay, M. (2008). The danger of workplace gossip. Careerstone Group, (2).

Andersson, L.M., \& Pearson, C.M. (1999). Tit for tat? The spiraling effect of incivility in the workplace. The Academy of Management Review, 24(3), 452-471.

Baron, R.A. \& Neuman, J.H. (1998). Workplace aggression--The iceberg beneath the tip of workplace violence: Evidence on its forms, frequency, and targets. PAQ, Winter, 447464.

Barlett, J.E., III, Barlett, M.E., \& Reio, T.G., Jr. (2008).Workplace Incivility: Worker and Organizational Antecedents and Outcomes. Academy of Human Resource Development International Research Conference in the Americas (Winter 2008). Retrieved from http://www.eric.ed.gov/ERICWebPortal/

Bolman, L.G., \& Deal, T.E. (2008). Reframing Organizations: Artistry, choice, and leadership. $\left(4^{\text {th }}\right.$ ed). San Francisco. Jossey-Bass.

Carnegie Classification, F. (2010). The Carnegie foundation for the advancement of teaching. Retrieved 8th February, 2012: http://classifications.carnegiefoudnation.org/lookup/.

Carter, S.L. (1998). Civility: manners, morals, and the etiquette of democracy. New York, London, Toronto, Sydney. Harper-Perennial.

Chen, P.Y. \& Spector, P.E. (1992). Relationships of work stressors with aggression, withdrawal, theft and substance abuse: An exploratory study. Journal of Occupational and Organizational Psychology, 65, 177-184.

Collins, S. (2009). Managing Conflict and Workplace Relationships. (2 ${ }^{\text {nd }}$ ed.). South-Western Cengage Learning, US. 
Cortina, L.M, Magley, V.J., Williams, J. H., \& Langout, R.D. (2001) Incivility in the workplace: Incidence and impact. Journal of Occupational Health Psychology, 6(1), 64-80.

Davidson, J., \& Wood, C. (2004). A conflict resolution model. Theory into Practice 43(1), 6-13.

Deutsch, M., Coleman, P.T., \& Marcus, E.C. (2006). The handbook of conflict resolution:Theory and practice. ( $2^{\text {nd }}$ ed.). San Francisco, Jossey-Bass.

Ferriss, A.L. (2002). Studying and measuring civility: A framework, trends, and scale. Sociological Inquiry, 72(3), 376-392.

Field, A. (2009). Discovering statistics: using SPSS. California: Sage Publications, $3^{\text {rd }}$ ed.

Fisher, R. (2000). Sources of conflict and methods of conflict resolution. School of International Service, The American University, 1-6.

Forni, P.M. (2008). The Civility Solution: What to Do When People Are Rude. New York, St. Martin's Press.

Fox, S., Spector, P.E., \& Miles, D. (2001). Counterproductive workplace behavior (CWB) in response to job stressors and organizational justice: some mediator and moderator tests for autonomy and emotions. Journal of Vocational Behavior, 59, 291-309.

Fox, S. \& Stallworth, L.E. (2003). Racial/ethnic bullying: exploring links between bullying and racism in the US workplace. Journal of Vocational Behavior, 66(3), 438-456.

Glomb, T.M. \& Liao, H (2003). Interpersonal aggression in work groups: Social influence, reciprocal and individual effects. The Academy of Management Journal, 46(4), 486-496.

Goffman, E. (1959). The presentation of self in everyday life. New York: Doubleday.

Griffin, R.W., O’Leary-Kelly, A., \& Collins, J.M. (1998). Dysfunctional behavior in organizations: Violence and deviant behavior. Stamford, CT: J\&J Press. 
Hornstein, H. (2003). Workplace incivility: An unavoidable product of human nature and organizational nurturing. Ivey Business Journal, 68(2), 1-7.

Kefela, G.T. (2010). Understanding organizational culture and leadership — enhance efficiency and productivity. PM World Today, 12(1), 1-14.

Kendig, S.M., \& Chapman, P.E. (2012). Administrator and faculty perceptions of incivility and conflict: A higher education study. Unpublished manuscript, Department of Curriculum \& Instruction/Literacy Studies, West Virginia University, Morgantown, West Virginia.

Kimmel, P.R. (1995). Culture and conflict. In M. Deutsch, P. Coleman, \& E. Marcus (eds.), The Handbook of Conflict Resolution. San Francisco: Jossey-Bass.

Kreitner, R. (1980). Management: A problem solving process. Boston: Houghton-Mifflin.

Layne, E. (2013). The damage of gossip in the workplace. Retrieved $9^{\text {th }}$ January, 2013: http://smallbusiness.chron.com/damage-gossip-workplace-15218.html.

Marks, J. (1996). The American uncivil wars. U.S. News and World Report, April 22, 66-72.

Martin, R.J. \& Hine, D.W. (2005) Development and Validation of the Uncivil Workplace Behavior Questionnaire, Journal of Occupational Health Psychology, 4.

Mayer, B.S. (2000) The Dynamics of Conflict Resolution: A Practitioner's Guide. San Francisco, CA: Jossey-Bass.

Mertz, G., \& Lieber, C. Miller. (2004). Five dimensions of conflict. Educators for Social Responsibility, 29, 1-6.

Moore, C.W. (1996). The Mediation Process: Practical Strategies for Resolving Conflict. $2^{\text {nd }}$ ed. San-Francisco, CA: Jossey-Bass.

Namie, G., \& Namie, R. (2000). The Bully at Work: What you can do to stop the hurt and reclaim your dignity on the job. $2^{\text {nd }}$ ed. Illinois, Sourcebooks, Inc. 
Nord, W. (1972). Culture and organizational behavior, in concepts and controversy. Goodyear, 178.

Pearson, C., Andersson, L., \& Porath, C. (2000). Assessing and attacking workplace incivility. Organizational Dynamics, 29, 123-137.

Pearson, C., \& Porath, C. (2005). On the nature, consequences and remedies of workplace incivility: No time for "nice"? Think again, Academy of Management Review, 19, 7-18.

Penney, L., \& Spector, P. (2005). Job stress, incivility, and counterproductive work behavior (CWB): The moderating role of negative affectivity, Journal of Organizational Behavior, 26(7), 777-796.

Pierre, R. Jr., \& Peppers, J.G., Jr. (1976). Conflict in organizations: good or bad. Air University Review, November-December, 1-11.

Pietersen, P.C. (2005). A diagnostic approach to measuring and managing workplace aggression. Journal of Human Resource Management, 3(1), 1-5.

Rahim, M.A. (2011). Managing conflict in organizations. ( $4^{\text {th }}$ ed.). New Brunswick. Transaction Publishers.

Robinson, S.L. \& Bennett, R.J. (1995). A typology of deviant workplace behaviors: A multidimensional scaling study. Academy of Management, 38(2), 555-572.

Robinson, S.L. \& O’Leary-Kelly, A.M. (1998). Monkey see, monkey do: The influence of work groups on the antisocial behavior of employees. The Academy of Management Journal, $41(6), 658-672$

Romano, C. (1994). Workplace violence takes a deadly turn. Management Review, 83(7), 5.

Schein, E.H. (2010). Organizational culture and leadership. $\left(4^{\text {th }}\right.$ ed.). San Francisco, CA: Jossey-Bass. 
Seldin, P. (1984). Changing practices in faculty evaluation: A critical assessment and recommendations for improvement. San Francisco: Jossey-Bass.

Senge, P.M. (2006). The fifth discipline: The art \& practice of the learning organization. United States. Doubleday Publishing.

Seymour, C. (2003). Social psychological dimensions of conflict: beyond intractability. Conflict Resource Consortium, University of Colorado, Boulder.

Sills, S.J. \& Song, C. (2002). Innovations in survey research: An application of Web surveys. Social Science Review 20, 22-30.

Somers, P., Cofer J., Austin, J.L., Inman, D., Martin, T., Rook, S., Stokes, T., \& Wilkinson, L. (1998). Faculty and staff: the weather radar of campus climate. New Directions for Institutional Research, 98, 35-52.

Spector, P.E. \& Fox, S. (2002). An emotion-centered model of voluntary work behavior: some parallels between counterproductive work behavior (CWB) and organizational citizenship behavior (OCB). Human Resources Management Review, 12, 269-292.

Tierney, W.G. (1988). Organizational culture in higher education: defining the essentials. The Journal of Higher Education, 59(1), 2-21.

Triandis, H.C. (1989). The self and social behavior in differing cultural contexts. Journal of Psychological Review, 96, 506-520.

Twale, D.J., \& DeLuca, B.M. (2008). Faculty Incivility: The rise of the academic bully culture and what to do about it. San Francisco, CA: Jossey-Bass.

Vega, G., \& Comer, D.R. (2005). Sticks and stones may break your bones, but works can break your spirit: bullying in the workplace. Journal of Business Ethics, 58(1/3), 101-109.

Wall, J.A. \& Calliser, R.R. (1995) Conflict and Its Management. Journal of Management, 21(3), $515-558$. 


\section{Appendix A: Uncivil Workplace Behavior Questionnaire (Martin \& Hine, 2005)}

During the past twelve months, or as long as you have been with your current institution, how often have you been is a situation where a colleague:

(Please circle the relevant answer in the right column)

1=never, $2=$ rarely, $3=$ occasionally, 4=often, 5=very often

1. Avoided consulting you when they would normally be expected to do so $(1,2,3,4,5)$

2. Talked about you behind your back

3. Was excessively slow in returning your phone message or emails without good reason for the delay $(1,2,3,4,5)$

4. Used an inappropriate tone when speaking to you $(1,2,3,4,5)$

5. Was unreasonably slow in dealing with matters important to your work $(1,2,3,4,5)$

6. Gossiped behind your back $(1,2,3,4,5)$

7. Opened your desk drawers without permission from you $(1,2,3,4,5)$

8. Publically discussed your confidential personal information $(1,2,3,4,5)$

9. Took items from your desk without your permission $(1,2,3,4,5)$

10. Spoke to you in an aggressive tone of voice $(1,2,3,4,5)$

11. Intentionally failed to pass on information that you should have had $(1,2,3,4,5)$

12. Made snide remarks about you $(1,2,3,4,5)$

13. Took stationary from your desk without replenishing it $(1,2,3,4,5)$

14. Read your personal communications such as emails $(1,2,3,4,5)$

15. Raised their voice while speaking to you $(1,2,3,4,5)$

16. Did not consult you regarding a decision you should have been involved in $(1,2,3,4,5)$

17. Rolled their eyes at you $(1,2,3,4,5)$

18. Interrupted you while you were on the phone $(1,2,3,4,5)$

19. Gave unreasonably short notice when canceling or scheduling events you were required to be present for.

$(1,2,3,4,5)$

20. Failed to inform you of a meeting you should have been informed about $(1,2,3,4,5)$ 


\section{Appendix B: The K and C Organizational Culture Instrument}

Please circle the relevant answer in the right column (Strongly Agree (SA), Agree (A), Disagree (D), or Strongly Disagree (SD).

1. The mission statement for my institution is well defined and articulated. (SA A D SD)

2. The leaders at my institution are well defined and approachable.

(SA A D SD)

3. My institution has the reputation of being a great place to work.

4. The mission statement for my institution is not useful.

(SA A D SD)

5. My work environment has the tendency to be emotionally and mentally hostile.

6. Leaders at my institution make their expectations clear.

(SA A D SD)

7. I consider my institution's culture to be friendly.

(SA A D SD)

8. It is my perception that administrators and faculty members at my institution work collaboratively to reach the institution's goals.

(SA A D SD)

9. I believe that administrators refer to my institution's mission statement for decision making purposes.

(SA A D SD)

10. Leaders at my institution do not often include faculty input in decision making situations. (SA A D SD)

11. The reputation of my institution stifles recruitment efforts of quality administrators and faculty.

(SA A D SD)

12. It is my perception that the mission statement for my institution is understood and embraced by faculty members.

(SA A D SD) 


\section{Appendix C: Permission to use UWBQ Instrument}

Hi Stacey,

Thanks for your interest in our research. Relevant article and instrument attached. Please feel free to use or modify as you see fit.

Best wishes,

Don

On 21/06/11 2:01 AM, "Stacey Kendig" <skendig@ @shepherd.edu> wrote:

Good Afternoon Dr. Hine;

I am a doctoral student at West Virginia University and beginning my dissertation process. My topic is very broad at this juncture however will be developed around the growing concern of Incivility in Higher Education. As I have been building my literature for review, I came across another dissertation with a similar topic. Upon reviewing this piece, I see that your Uncivil Workplace Behavior Questionnaire was used.

I am not familiar with your instrument, but am interested in reviewing it to see if it would be an instrument suitable for my dissertation purposes. Is it possible to purchase a sample?

Your time and consideration is greatly appreciated.

Thank you

Stacey

Mrs. Stacey M. Kendig

Asst. Professor of Recreation and Sport Studies

Department of Health, Physical Education, Recreation and Sport

Shepherd University

skendig@shepherd.edu 


\section{Appendix D: Administrator Cover Letter}

From: $\quad$ skendig@shepherd.edu

Subject: Uncivil Workplace Behavior Questionnaire

The K \& C Organizational Culture Instrument

Dear Administrator:

Incivility in the higher education academic environment is counterproductive for achieving the institutional goals. There has been limited research in reference to administrator perceptions of uncivil behaviors and institutional culture and the relationship to conflict in higher education. Therefore, I am requesting your participation in the examination of these two essential parts of your leadership role. This study is voluntary and requires that participants be 18 years of age or older. This study is a partial requirement for the completion of my doctoral studies in Educational Leadership in Higher Education at West Virginia University.

This study explores the sources, dimensions, and causes of uncivil behaviors as they relate to conflict within institutions of higher education. Moreover, the study also explores administrator and faculty perceptions of conflict within their institution and the relationship to institutional culture. There are two instruments combined for use of this study. The survey takes approximately five to ten minutes to complete. This research has been approved by the West Virginia University Internal Review Board (IRB). The names of all participants and institutions will remain completely anonymous throughout the study and the final research report. Your completed instruments will be identified by a code for follow-up purposes only. Your participation in this study is voluntary but will be greatly appreciated.

If you have questions regarding this study, please contact me via e-mail at skendig@shepherd.edu. You may also contact my dissertation committee chair, Dr. Paul E. Chapman at Paul.Chapman@mail.wvu.edu. A summary of the study and findings will be forwarded to you at your request.

Your time and consideration for participating in this study is greatly appreciated.

Sincerely,

Stacey M. Kendig

Doctoral Candidate

West Virginia University

Educational Leadership in Higher Education 


\section{Appendix E: Administrator Reminder Letter}

From: $\quad$ skendig@shepherd.edu

Subject: $\quad$ The Uncivil Workplace Behavior Questionnaire \& The K \& C Organizational Culture Instrument

Dear Administrator:

This is a courtesy reminder request for your participation in the Uncivil Workplace Behavior Questionnaire with The K \& C Organizational Culture Instrument. The original request to participate in this study was sent out June 28,2012 . If you have already completed the electronic survey, your participation is greatly appreciated. If you have not completed the electronic survey, your participation is an important element for the completion of my study. This research has been approved by the West Virginia University Institutional Review Board.

The names of all participants and institutions will remain completely anonymous throughout the study and the final research report. Your participation in this study is voluntary and is greatly appreciated. You can access the survey by clicking on the link below this message.

If you have questions regarding this study, please contact me via e-mail at skendig@shepherd.edu. You may also contact my dissertation committee chair, Dr. Paul E. Chapman at Paul.Chapman@mail.wvu.edu. Thank you for your participation and assistance in the completion of my study.

Sincerely,

Stacey M. Kendig Doctoral Candidate West Virginia University

Educational Leadership in Higher Education 


\section{Appendix F: Faculty Cover Letter}

From: skendig@shepherd.edu

Subject: Uncivil Workplace Behavior Questionnaire

The K \& C Organizational Culture Instrument

Dear Faculty Member:

Incivility in the higher education academic environment is counterproductive for achieving the institutional goals. There has been limited research in reference to administrator perceptions of uncivil behaviors and institutional culture and the relationship to conflict in higher education. Therefore, I am requesting your participation in the examination of these two essential parts of your leadership role. This study is voluntary and requires that participants be 18 years of age or older. This study is a partial requirement for the completion of my doctoral studies in Educational Leadership in Higher Education at West Virginia University.

This study explores the sources, dimensions, and causes of uncivil behaviors as they relate to conflict within institutions of higher education. Moreover, the study also explores administrator and faculty perceptions of conflict within their institution and the relationship to institutional culture. There are two instruments combined for use of this study. The instrument will take approximately five to ten minutes to complete. This research has been approved by the West Virginia University Internal Review Board (IRB). The names of all participants and institutions will remain completely anonymous throughout the study and the final research report. Your completed instruments will be identified by a code for follow-up purposes only. Your participation in this study is voluntary but will be greatly appreciated.

If you have questions regarding this study, please contact me via e-mail at skendig@shepherd.edu. You may also contact my dissertation committee chair, Dr. Paul E. Chapman at Paul.Chapman@mail.wvu.edu. A summary of the study and findings will be forwarded to you at your request.

Your time and consideration for participating in this study is greatly appreciated.

Sincerely,

Stacey M. Kendig

Doctoral Candidate

West Virginia University

Educational Leadership in Higher Education 


\section{Appendix G: Faculty Reminder Letter}

From: $\quad$ skendig@shepherd.edu

Subject: $\quad$ The Uncivil Workplace Behavior Questionnaire \& The K \& C Organizational Culture Instrument

Dear Faculty Member:

This is a courtesy reminder request for your participation in the Uncivil Workplace Behavior Questionnaire with The K \& C Organizational Culture Instrument. The original request to participate in this study was sent out June 28,2012 . If you have already completed the electronic survey, your participation is greatly appreciated. If you have not completed the electronic survey, your participation is an important element for the completion of my study. This research has been approved by the West Virginia University Institutional Review Board.

The names of all participants and institutions will remain completely anonymous throughout the study and the final research report. Your participation in this study is voluntary and is greatly appreciated. You can access the survey by clicking on the link below this message.

If you have questions regarding this study, please contact me via e-mail at skendig@shepherd.edu. You may also contact my dissertation committee chair, Dr. Paul E. Chapman at Paul.Chapman@mail.wvu.edu. Thank you for your participation and assistance in the completion of my study.

Sincerely,

Stacey M. Kendig Doctoral Candidate West Virginia University

Educational Leadership in Higher Education 